\title{
Open-Access Crime Maps as Digital Rhetoric and Crime Reporting in Chicago: Using New Aesthetic Overlaps to Change Journalism and Citizen Interaction
}

Aaron Geiger

Follow this and additional works at: https://researchrepository.wvu.edu/etd

\section{Recommended Citation}

Geiger, Aaron, "Open-Access Crime Maps as Digital Rhetoric and Crime Reporting in Chicago: Using New Aesthetic Overlaps to Change Journalism and Citizen Interaction" (2017). Graduate Theses, Dissertations, and Problem Reports. 5657.

https://researchrepository.wvu.edu/etd/5657

This Thesis is protected by copyright and/or related rights. It has been brought to you by the The Research Repository @ WVU with permission from the rights-holder(s). You are free to use this Thesis in any way that is permitted by the copyright and related rights legislation that applies to your use. For other uses you must obtain permission from the rights-holder(s) directly, unless additional rights are indicated by a Creative Commons license in the record and/ or on the work itself. This Thesis has been accepted for inclusion in WVU Graduate Theses, Dissertations, and Problem Reports collection by an authorized administrator of The Research Repository @ WVU. For more information, please contact researchrepository@mail.wvu.edu. 
Open-Access Crime Maps as Digital Rhetoric and Crime Reporting in Chicago: Using New Aesthetic Overlaps to Change Journalism and Citizen Interaction

\author{
Aaron Geiger \\ Thesis submitted to the Reed College of Media \\ at West Virginia University \\ in partial fulfillment for the degree of \\ Master of Science in \\ Journalism \\ Bob Britten, Ph.D., Chair \\ Steve Urbanski, Ph.D. \\ David Smith, M.A. \\ Jon Stone, Ph.D. \\ Department of Journalism \\ Morgantown, West Virginia \\ 2017
}

Keywords: map; maps; rhetoric; cartography; algorithmic rhetoric; journalism; police; crime; race; socioeconomics; demographics; New Aesthetic; digital rhetoric

Copyright 2017 Aaron Geiger 


\title{
ABSTRACT \\ Open-Access Crime Maps as Digital Rhetoric and Crime Reporting in Chicago: Using New Aesthetic Overlaps to Change Journalism and Citizen Interaction
}

\begin{abstract}
Aaron Geiger
When data mining meets the rhetoric of maps and crowdsourcing in the age of digital journalism, we can use the abundance of data to change, modify or reinforce particular reporting behaviors or journalism policies. We also live in an age of overlapping boundaries of technologies, algorithms and human interfaces - it is within these overlaps that we find anomalies, "glitches," and digital errata that can expose different perceptions of the same artifacts and algorithms. The overlapping of the heterogeneous network, as James Bridle calls it, is known as The New Aesthetic. It is not a movement, but "a series of artifacts ... which recognize differences, the gaps in our distant but overlapping realities." One real life example is the exploration of Chicago crime reporting via the Chicago Tribune, compared to the police-sourced CrimeReports.com, and how metadata might reshape the nature of how crime is reported, using digital crime mapping analysis and digital rhetorical analysis to find glitches and anomalies - where our communications with the mathematical, visual and computational facets of technology often produce surprising results. In turn, the public will receive a new perspective and offer a feedback loop to the newspaper. Crowd-sourced citizen reporting augments police reports, creating a collaborative set of data, change the face of sensationalism and return crime reporting to a basic data-driven level. In short, crime reporting will become organic, and one outcome might be that the citizens will put more trust back into established newspapers for the production of mass data and innovative practices. Additionally, the use of digital cartography is explored here as yet another tool to engage the social media user, while benefitting the news media source.
\end{abstract}




\section{Table of Contents}

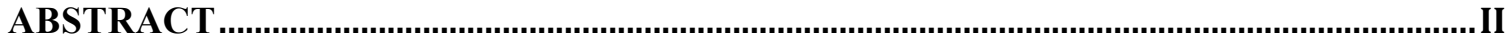

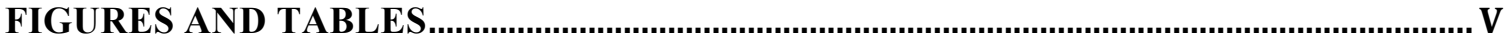

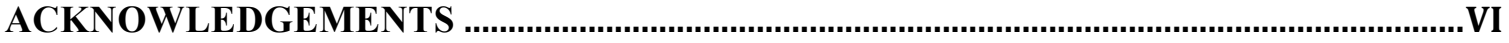

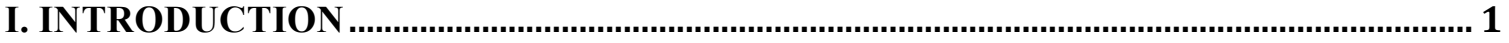

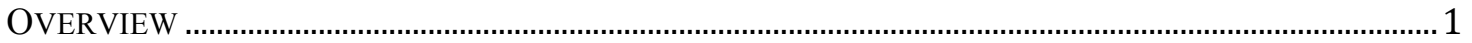

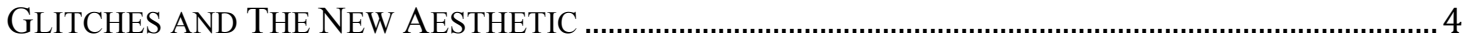

GLITCHES AND ONLINE NEWS MEDIA ………......................................................................... 5

NEWS MEDIA AND CRIME DISTORTION IN THE COMMUNITY …….................................................. 5

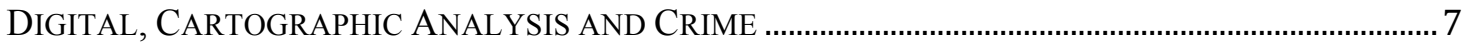

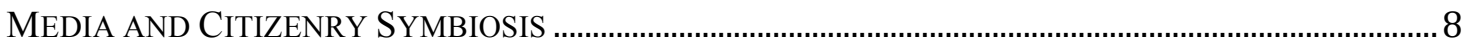

II. REVIEW OF LITERATURE

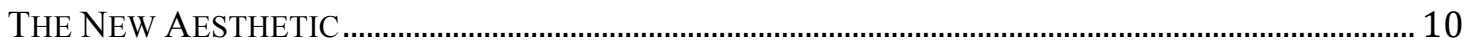

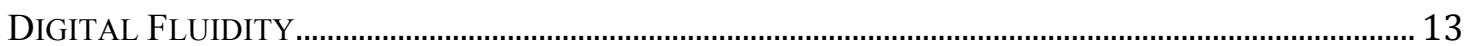

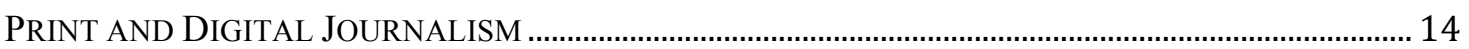

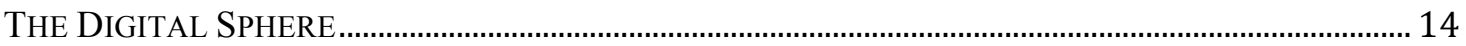

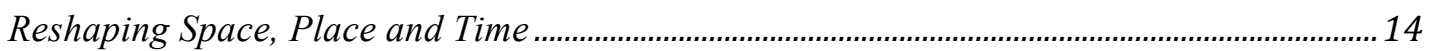

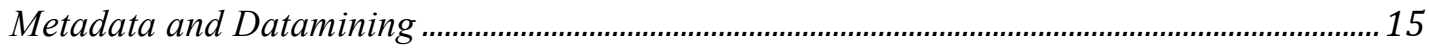

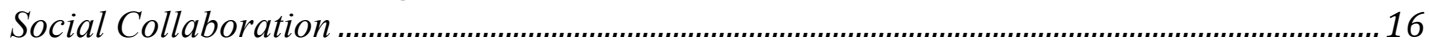

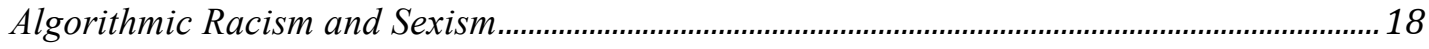

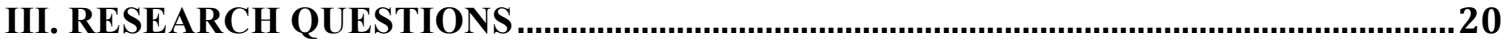

IV. METHODOLOGY

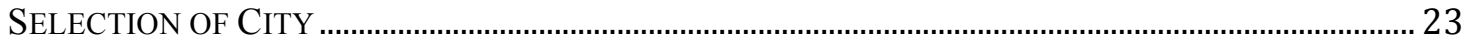

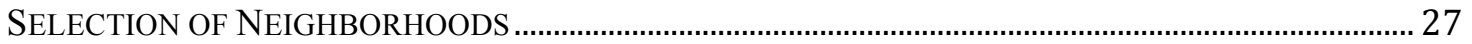

TYPES OF CRIMES

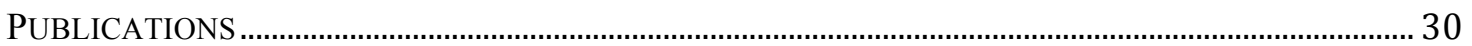

V. FINDINGS

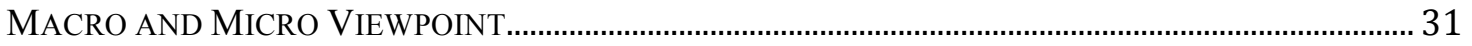

Initial Findings

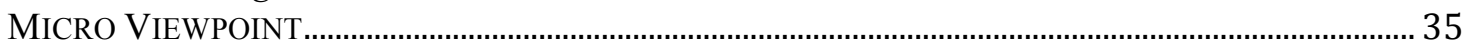

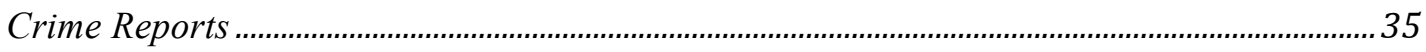

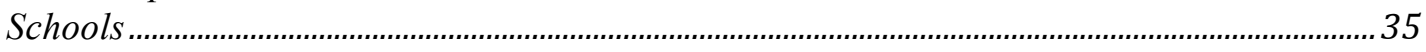

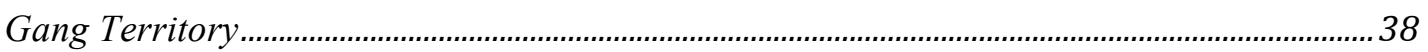

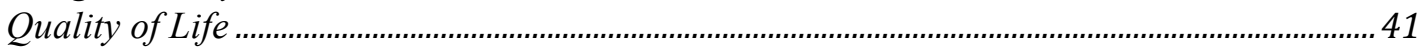

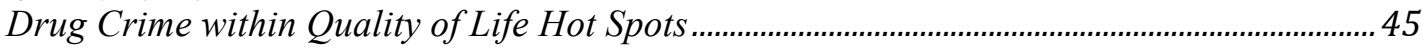

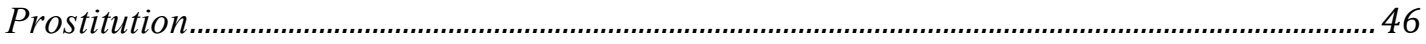

Arson

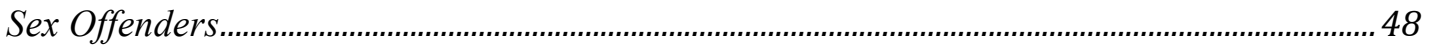

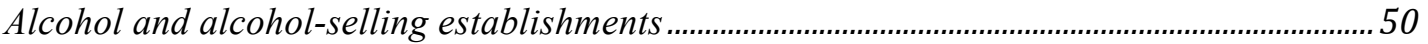

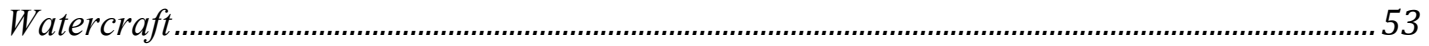

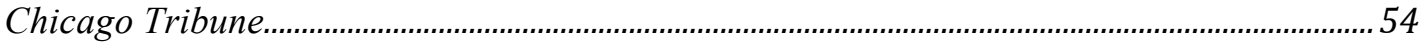

West Side Chicago (Humboldt Park, East Garfield, West Garfield)..........................................55

South Side Chicago (New City, West Englewood, East Englewood)........................................55

Wrigleyville (Uptown, Lake View, Lincoln Park) ..................................................................... 56

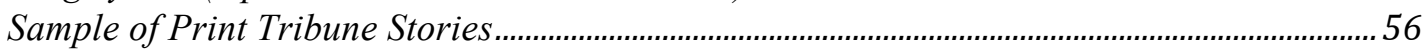

Logging Digital Tribune Crime Reporting ................................................................................ 58 
Summary

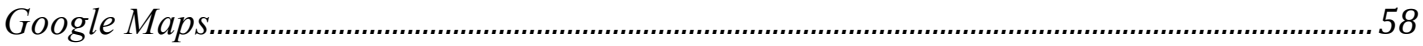

VI. DISCUSSION

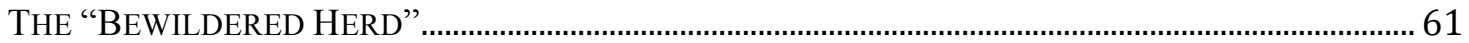

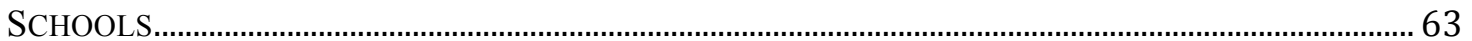

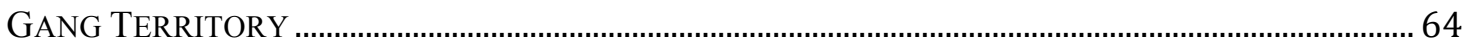

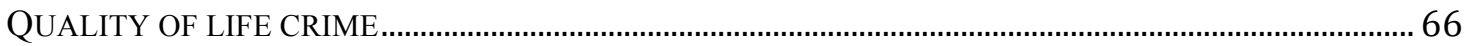

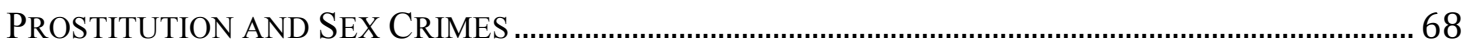

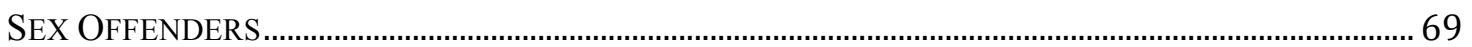

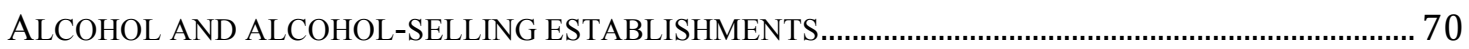

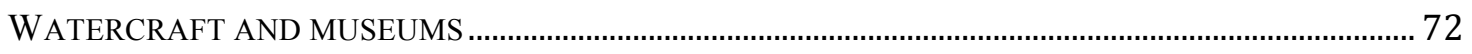

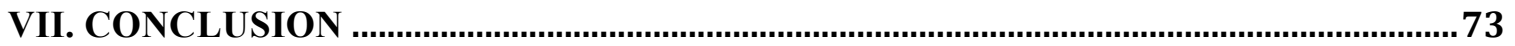

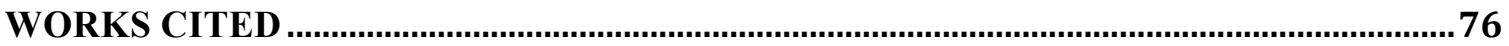




\section{FIGURES AND TABLES}

FIGURE 1. EXAMPLE OF INNOVATION FROM OVERLAPPING BOUNDARIES. ................................................ 3

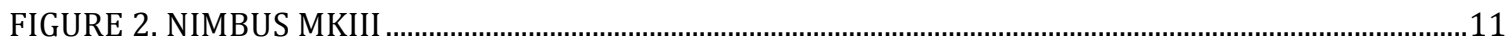

FIGURE 3. NIMBUS MKIII'S FACIAL-RECOGNITION PHOTO ……..............................................................12

FIGURE 4. TWO-DAY SAMPLE OF THE CHICAGO TRIBUNE'S CRIME REPORTING DATA, PLOTTED

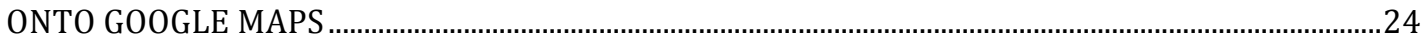

FIGURE 5. CHICAGO TRIBUNE'S CRIME REPORTING DATA, PLOTTED ONTO GOOGLE MAPS; WITH BRIEF DETAIL ON ONE SPECIFIC CRIME AFTER CLICKING ON ONE OF THE PINS..........................25

FIGURE 6. 1000-FOOT BUFFER OF GLENDALE SCHOOLS. A DISTANCE ANALYSIS OF CRIME PLOTS

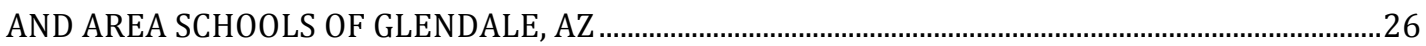

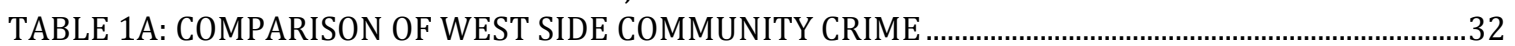

TABLE 1B: COMPARISON OF SOUTH SIDE COMMUNITY CRIME ....................................................................32

TABLE 1C: COMPARISON OF WRIGLEYVILLE COMMUNITY CRIME …………….........................................32

FIGURE 7: HOPE ACADEMY SCHOOL CRIME BUFFER …….........................................................................

FIGURE 8. BASS ELEMENTARY SCHOOL CRIME BUFFER ……………………………………………….....37

FIGURE 9. LOSS OF BENJAMIN BANNEKER SCHOOL CRIME BUFFER ………………………………….......38

FIGURE 10. CHICAGO GANGS MAPS OF TRADITIONAL AND MICRO GANG TERRITORIES, 2014 .........40

FIGURE 11. GANG CROSSOVER CRIME IN ENGLEWOOD ............................................................................

FIGURE 12. WEST GARFIELD, NEAR EISENHOWER EXPRESSWAY, QUALITY OF LIFE CRIME .............43

FIGURE 13. HUMBOLDT PARK, NEAR HUMBOLDT PARK AND GRAND AVENUE, QUALITY OF LIFE

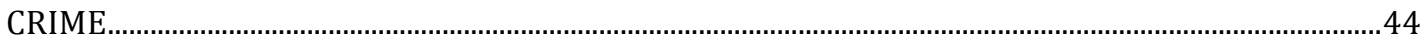

FIGURE 14. HUMBOLDT PARK DRUG CRIMES …….........................................................................................46

FIGURE 15. WEST ENGLEWOOD PROSTITUTION AND SEX ASSAULT CLUSTER .........................................47

FIGURE 16. ARSON CLUSTER IN THE ISLAND...................................................................................................48

FIGURE 17. REGISTERED SEX OFFENDERS OF HUMBOLDT PARK ……………...........................................49

FIGURE 18. SEX OFFENDER CONCENTRATION OF HUMBOLDT PARK.........................................................50

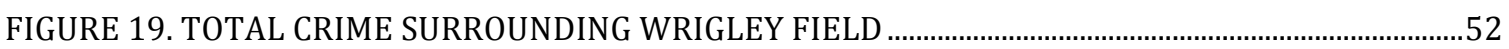

FIGURE 20. WRIGLEY FIELD DURING BASEBALL OFF-SEASON: FEB. 1 -.MARCH 4, 2017 ....................52

FIGURE 21. THEFTS FROM WATERCRAFT, BUILDINGS, AND VEHICLES AT BELMONT HARBOR........53

FIGURE 22. LIST OF SCHOOL CLOSURES FROM CPS (CHICAGO TRIBUNE, 2013) .....................................64

FIGURE 23. CPS SCHOOL CLOSURE REPORT CARD (CHICAGO TRIBUNE, 2013) .......................................64 


\section{ACKNOWLEDGEMENTS}

To my thesis committee:

Dr. Bob Britten: For your continued prodding and assistance, for administering challenges, for provoking academic curiosity, and for your many hours of editing and mentorship, I remain grateful and shall pay these traits forward in my career.

Dr. Steve Urbanski: Your candor and mentorship has been invaluable to me. Thank you for being the face of the Reed College of Media - your capacity as ambassador to graduate students, and to me, has been life changing. Thank you.

Dr. Jon Stone: As an undergraduate student at the University of Illinois I found myself greatly impacted by my then-Writing Across the Curriculum instructor, and found that teaching with enthusiasm and genuine earnestness can be instrumental in reaching students. As my at-large thesis committee member, you completed a circle of academic curiosity. Thank you for your continued support, wisdom, and inspiration.

Mr. David Smith: Thank you so very much for your assistance, questions, edits, and for stepping in to carry this thesis, and my career, forward. I wish you the best as you prepare more students for the future.

To my family:

My mother, Katie, fostered an intellectual hunger in me through our mutual love of books and the world around us. My father, Stephen, raised me to be self-aware and to be aware of others, and work hard. The combination of these qualities directly influenced my desire to learn and pass the love of learning on to my children and my students - to be curious and aware, and to facilitate these things with a strong work ethic.

My in-laws, Glenna and Michael, and wife's grandparents, Dixie and Dan, donated their time, energy, and money to provide me with ample time to read, write, conduct research, attend classes, and travel on behalf of academic endeavors. They watched my young children, nurtured them, and loved them. I am forever in their debt.

To my wife, Dr. Sarah Dee, it is to you I offer the greatest appreciation. To our very long days, short nights, and travels across the country in pursuit of our schools and careerslife is sweetest when experienced fully. The best rest comes after a long day. Thank you for supporting me in all I do. 


\section{INTRODUCTION}

\section{Overview}

It is almost impossible to design an algorithm in such a way that it be used exclusively for its intended purpose - the more complex the algorithm, the higher the chance that it will not adhere to all commands. Additionally, technology and software overlap when humans interact with various devices and programs. Sometimes bizarre or unintended issues arise because of these overlaps. When a human writes computer code using a set of commands, the receiving computer, machine/robot or algorithm, in the words of Bruce Sterling, “don't and can't make sound aesthetic judgments ... [they] lack cognition. They lack perception. They lack taste. They lack intelligence. They lack ethics" (n.p. 2012). We cannot expect algorithms to behave. They are logical and follow hierarchal commands. However, as part of a complex system of competing technologies, billions of lines of conflicting code, and new machines that use algorithms, the phenomena of "glitches," or coding errata, often occur. The chronicling of these glitches is called the "New Aesthetic" (Bridle, 2011; Sterling, 2012).

However, when we already have complex algorithms in place (computer programs and applications, for example), we can create an overlap in technologichumanistic interaction. After Bridle coined the New Aesthetic at the South-by-Southwest Festival in 2011, he was already in the middle of the movement he put a name to. To wit: "The New Aesthetic is not a movement, it is not a thing which can be done, it is a series of artefacts of the heterogeneous network, which recognises differences, the gaps in our distant but overlapping realities" (n.p. Bridle, 2011). In London, artists began to 
creatively and artistically express New Aesthetic ideas through experimentation with overlaps (Plummer-Fernandez, 2015). Soon thereafter, the New Aesthetic was used for exploitative purposes, as citizens across the world attempted to break, confound, or glitch the limitations of algorithms by combining code, machinery, and human characteristics and culture (Bridle, 2011; Sterling, 2012; Plummer-Fernandez, 2015). As a result, new and unexpected results occurred during these processes that stimulated new methods of innovation and cataloguing. To be clear, while we may force technological boundaries or databases upon one another to provoke glitches, glitches are both unexpected and have unintended results. We may know that we are looking for an answer, but we don't know what that answer ultimately is, or how it may be used or interpreted.

Maps, in general, have routinely been exposed to this sort of manipulation. Global Fishing Watch, an organization that seeks to protect sea life from being overfished, combined the technology platforms of SkyTruth, Oceana, and Google to form a partnership that "illuminates" overfished areas from a satellite view (globalfishingwatch.org, 2014). The result is an easily accessible map that embodies massive amounts of data in illuminated areas around the world's seas for convenient viewing (Fig. 1). 


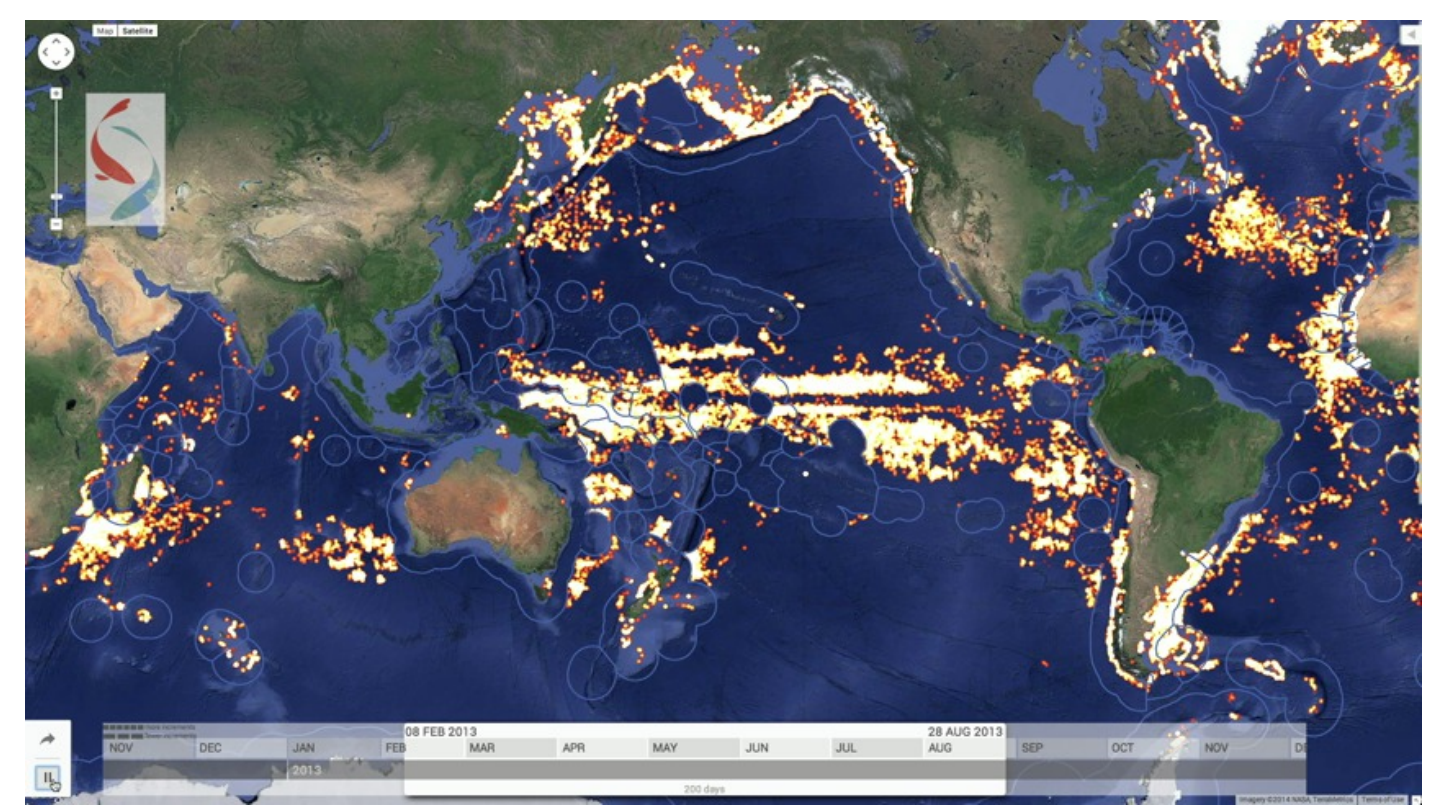

Figure 1. Illuminated points of light are Automatic Identification Systems (AIS) transponders used by ocean-going fishing vessels. These points of light articulate where fishing vessels are located (Google Storage, 2013; SkyWatch, 2013).

One area that is little studied under this framework is that of crime mapping, though crime mapping has existed and evolved for some time (Paynich \& Hill, 2010). The Chicago Tribune, a print and digital newspaper founded in 1847, has attempted to make several maps that plot crime data in the city of Chicago, including a smartphone application that logs homicides and locations. The maps are, however, two-dimensional, meaning they combine cartographic imagery with data plots. In the New Aesthetic's domain, this is very limited.

Crime Reports, a website that plots crime data from participating law enforcement organizations, cultivates more complex maps than the Tribune. If the Tribune is reporting crime, but only reports a very small fraction of the crime that occurs in Chicago, we can deduce that there is a perceived value to the crimes that are reported, and that those crimes are higher in value than the crimes that are not reported. If we were to combine Crime Reports, which is also a two-dimensional map with the Chicago Tribune's crime reporting, we can examine overlaps in differences, such as from where the Tribune's staff 
report crime news, what they're reporting, how extensively, etc. Aberrant discrepancies in the overlaps are called glitches, and, as the glitches are catalogued and chronicled, new information may come to light.

\section{Glitches and The New Aesthetic}

One example of the New Aesthetic chronicling a glitch would be the case of a married couple who decided to share their Nike+ FuelBand information with each other. Nike+ FuelBand is wearable technology that tracks calories, movements, heart rates, and other biorhythmic activity. The wife discovered her husband was cheating on her when his FuelBand reported that he was exceptionally "active" at $12-1$ am in the morning when he was supposed to be home, asleep (HotHotware.com, 2012). As exemplified in the anecdote, glitches are unexpected, technical anomalies that are often connected with negative connotations - a mistake, aberration or misapplication.

However, Glitch Theory scholar Steven Hammer (2015) says that "[w]e must embrace glitches, mistakes, objections, and interruptions as necessary conditions of composition" (n.p.). The etymology of the word is unknown (OED, 2016), but it is an evolving term that began with voltage anomalies on space missions, television graphics issues, typography errata, etc. These unintended consequences can be negative, benign, provocative, humorous, or even innovative.

Glitches have unintended, innovative properties, too. Researchers, examining differing social media behaviors, developed tests to find out why social media users performed certain actions, while others didn't. The process led scholars to believe online behaviors correlated with personality type. One conclusion the team came to involved 
personality extroversion and the use of "emojis" or emoticons-pictures to convey mood or objects (Bai, Zhu, \& Cheng, 2012). A New Aesthetic artifact, emojis have replaced language that is difficult for linguistic algorithms to decipher-sarcasm being one of them (Birner, 2012). Emojis, however, have simplified language, just as infograms and maps have greatly reduced the need to understand complex data sets. While this discovery alone, the data is invaluable to sources such as Facebook, who can tailor advertisements that delve into extroverted activities toward those who use emojis. As more personality types are uncovered by glitch observations, more data can be extracted from users, making marketing more lucrative.

\section{Glitches and Online News Media}

Digital newspapers are prime models for probing for glitch behaviors using algorithms, bots, and applications: They serve as watchdogs for community issues, subsist on marketing products and campaigns, and serve the public. The newspapers also have the power of the community at hand because even moderately circulated newspapers reach thousands of people. There lie endless opportunities for digital newspapers to collaborate with their audiences to exploit these glitches in novel ways. What once could be viewed as a sudden anomaly could eventually achieve permanence for a digital news source.

\section{News Media and Crime Distortion in the Community}

From the perspective of a digital news source, the concept of crime reporting has not been representative of the community it serves. Kim and Abisaid (2015) said, branching off of research from Tichenor, et al., (1980) that the news media "mirror[s] the 
conditions of [community structure], including power conditions, and power alignments," while not presenting an accurate depiction of the diversity of the public they serve, nor do they "serve the public's needs" (p. 98). They noted that an abundance of research has paid attention to the "new media's overrepresentation of violent crimes, therefore changing public perception of crime"1 (p. 98). One example is the pubic stigma associated with public housing and crime, with reporters establishing "beats" within public housing sectors, such as with the development of Cabrini Greens in Southside Chicago. Paynich and Hill (2014) note that founding scholars of crime mapping C. Ray Jeffrey (1971) and Oscar Newman (1972) developed Crime Prevention Through Environmental Design (CPTED). They demonstrated through empirical data that increased news media and police presence have the opposite of their intended effect. When police cars and media vans are a constant presence, crime rises. Other artifacts add to this effect—CCTVs, drug stings, locks, barred windows, etc. When schools and urban developments are developed with landscaping, crime goes down.

With the advent of comprehensive crime reporting, a digital newspaper can focus on sensational crimes while simultaneously providing crime reports that are communitybased. These, in theory, would bolster Jeffrey and Newman's empirical data.

To sum, glitches are unexpected technical aberrations caused by overlapping and competing technologies. Glitches are may be unwanted at times, but sometimes they can reveal new possibilities. In the news media, a glitch may provide a valuable way of

\footnotetext{
${ }^{1}$ For further reading on the overrepresentation of violent crimes, see: Antunes \& Hurley, 1977; Lipschultz \& Hilt, 2002; Maguire, Sandage, \& Weatherby, 1999; Roshier, 1973; Sheley \& Ashkins, 1981.
} 
communicating to or with audiences. In fact, there is an emerging population of artists and programmers that look to exploit glitches for their negative and positive properties.

\section{Digital, Cartographic Analysis and Crime}

Interactive maps transcend visual rhetoric by way of multimodality, using crowdsourced data, links, manipulative visual icons, etc. Hocks (2003) noted that hypertext, new media, and interactive digital texts remix visuals and words, the author and the audience, and the concepts of communication in postmodern interfaces. The classical notion of the rhetor-audience relationship, such as Plato's Phaedrus, where a fictional Socrates is mentoring his pupil on oral rhetoric after Phaedrus recounts an oral performance by Lysias (Bizzell \& Herzberg, 2001), is upended in the collaborative and digital nature of new media. Digital rhetoric is overtaking oral and written rhetoric. Digital cartography - a branch of digital rhetoric -follows the trajectory of an interactive nature, instantaneous feedback, and multimodal responses, which significantly change traditional oral and written rhetoric (Brooke, 2009).

The Chicago Tribune couldn't possibly report on most of the reported crime due to the volume of crime, budget concerns, ratings and time. However, a collective analysis might find patterns or voids for different crimes and identify areas that are not reported. Wrigleyville, also known as Lake View - the area around Wrigley Stadium - is over 75\% white and houses mostly affluent or semi-affluent residents as reported by income and property value (areavibes.com, 2016). Crime Reports shows significant crime in the area - assaults, vehicle theft, and other non-violent felonies. Conversely, South Side Chicago has been the site of failed, giant housing projects (such as Cabrini Green) and 
abject poverty in a mostly African-American population (city-data.com 2015). Homicide reporting in South Side is a staple of nighttime and morning news television and reporting (FOX 32, WTTW, CLTV, CBS Chicago, WGN, \& ABC 7, 2015). But according to Crime Reports, the volume of crime surrounding Wrigley Field appeared to exceed that of similar tracts of area in South Side communities (West Englewood, Englewood, and New City) from August 1 - Sept. 1, 2016. There is a trend of crime in both areas, which might lead criminologists and sociologists to ask questions such as, "What are the crimes being committed?" "What do both areas have in common in terms of crime-spawning factors?" "What is different—demographically, sociologically, architecturally, the ratio of police to persons, the access to employment and good schooling, etc.?" "Why is there little focus on the crime in Wrigleyville/Lakeville?" As part of this study, we must ask why the Tribune is not covering these types of crimes, and whether or not they should.

\section{Media and Citizenry Symbiosis}

This paper will ask the above questions while looking at other factors of New Aesthetic comparisons by changing simple visuals or written rhetoric into something concrete, tangible, interactive and productive for the Tribune to explore for the citizenry and readership, while collaborating with the readership. This symbiotic relationship is inclusive on both ends of digital, interactive discourse. As users add their own crime mapping data to a database, glitches in the new overlapping data will emerge. This research takes into account gender and racial bias via algorithms as developed by people who bring these biases with them when coding. Mapping provides empirical data that is 
not only accessible to the news media, but to the citizens and law enforcement, forming a symbiotic community. 


\section{REVIEW OF LITERATURE}

\section{The New Aesthetic}

James Bridle coined the term New Aesthetic, defining it as not a movement, but "a series of artefacts ... which recognise differences, the gaps in our distant but overlapping realities" (n.p., 2011). Because this line of discourse is only a few years old at the time of this writing, few scholarly and peer-reviewed resources directly address this analysis of "overlapping realities." Instead, we must circumvent these ideas by looking back to Greek and Roman rhetoric, technology, and digital humanism to form scholarly bridges and a framework to understand what Bridle and others mean.

Bridle called his definition the New Aesthetic, using "aesthetic" to mean, "What it looks like," rather than include it under the umbrellas of "art historical and critical discourse" (Bridle, 2013). This means New Aesthetic is an amalgamation of different technologies, mediums, algorithms and human interaction. In short, there are endless permutations of the technologies that we use, how we use them and where they might interact. We observe and chronicle and attempt to manipulate these permutations.

One example of design in the New Aesthetic would be Neil Usher's "Pareidolic Robot," which combines facial recognition software, two lenses (that function as "eyes"), a camera, and code written into algorithmic form (fig. 2). When a cloud drifts by and has a pattern that looks like a human face, the Pareidolic Robot algorithm reaches a coded threshold of human identity and triggers the camera, which takes a picture (fig. 3). Occasionally, Usher returned to download the pictures, and he published his results (Geere, 2012). This is a classic case of combining technologies to produce an overlap for a purpose other than its original intent —a feature harkening back to Greek philosopher 
Isocrates and inventio (Bizzell \& Herzberg, 2000). Facial recognition technology - used in some airports, for example, to aid in finding criminals - had never been used on clouds before, and a camera had never been used on top of those two technologies.

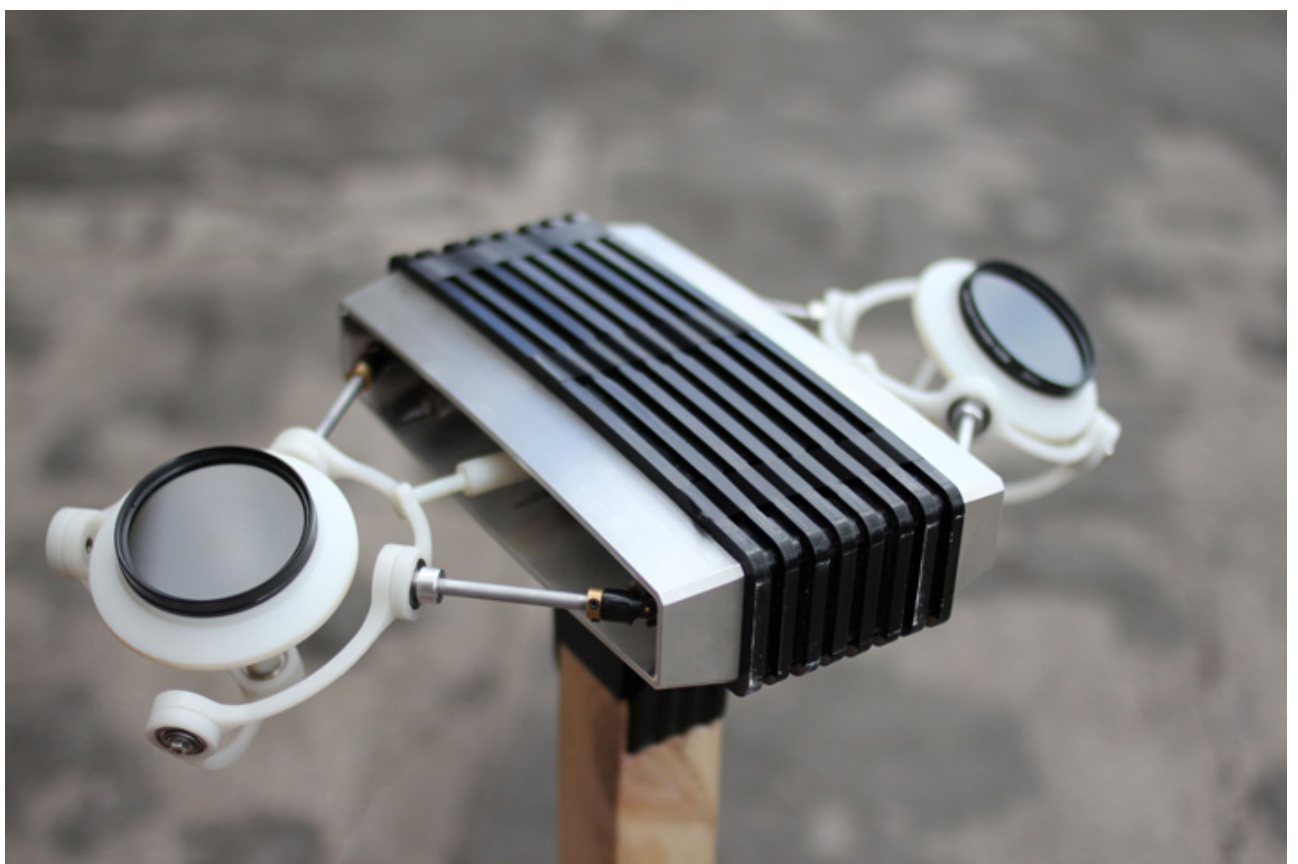

Figure 2. Nimbus MKIII (Usher, 2012). 


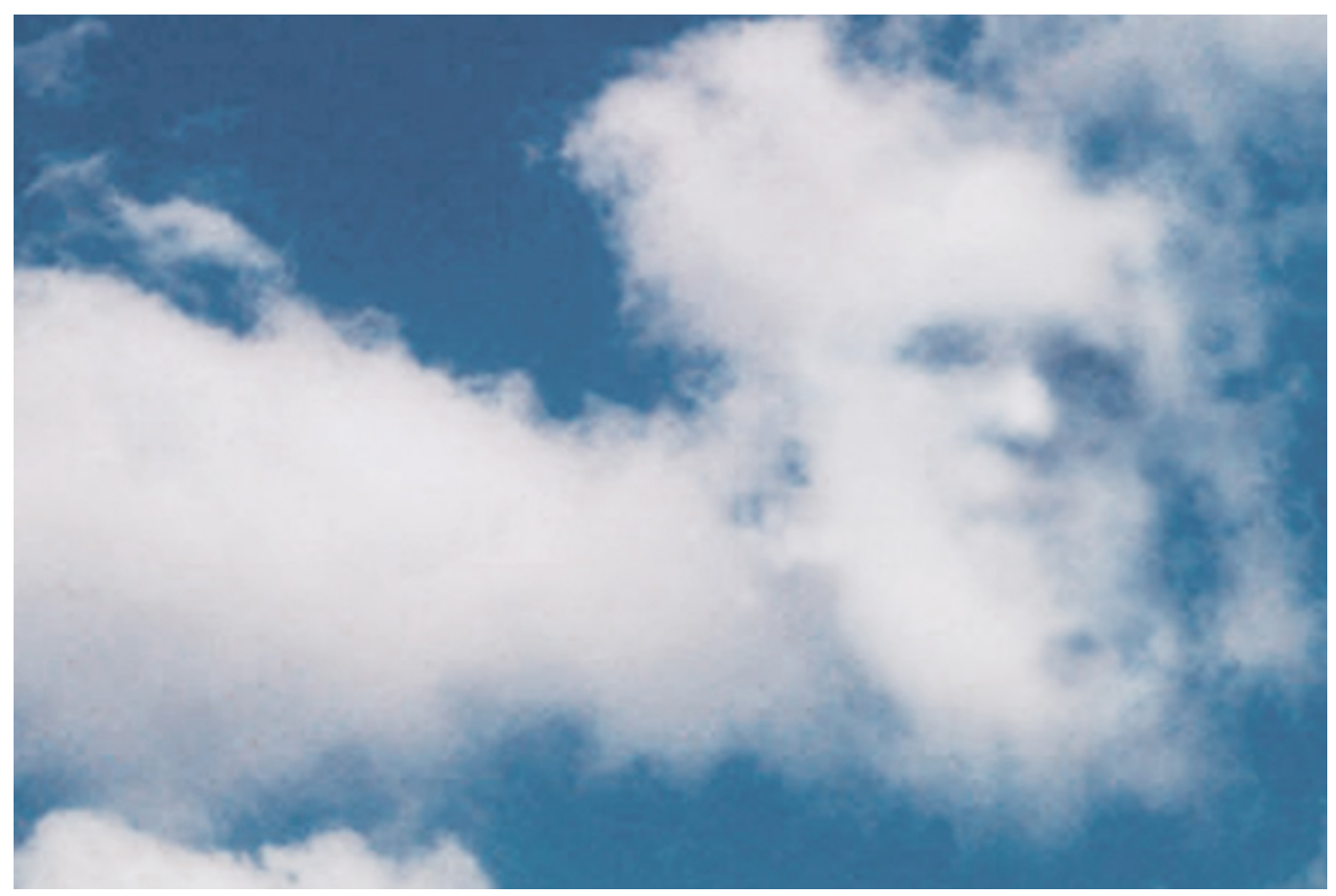

Figure 3. Nimbus MKIII's facial-recognition photo (Usher, 2012).

The New Aesthetic is an invaluable and emergent theoretical framework that allows the layperson to rethink foundational ideas to discover hidden problems primarily through the use of algorithms. Rhetorically, Bridle described technology interactions as being framed by humans as the understanding of human-crafted algorithms, technologies and interpretations. When we write an algorithm, for instance, we may attempt to have the algorithm perform a certain task on a particular piece of hardware, but that task might not function how we want it to when it is used on a different piece of hardware, or placed in a new contextual environment or digital ecosystem. When designing the algorithm, given the immensely large number of outcomes, it becomes nearly impossible to predict outcomes outside the parameters of that which the algorithm was used. The New Aesthetic looks outside of those intended purposes and finds alternative methods of examining the overlapping of designs and technology (Bridle, 2013). The overlaps in hardware, software, artifacts and humans are what define the New Aesthetic-we can 
either discover glitches by mixing mediums, or play the part of provocateur to force digital errata. By process of digital inventio, we can find true innovation.

\section{Digital Fluidity}

The digital sphere, like iterations of print or manuscripts, can be viewed, traditionally, like folds or leaves of pages in a book. Anderson and Sayers (2015) compared boundaries of written revisions to "folds among piles of fabric or sedimentary layers in the material world" (p. 80). Every digital visual is contained in a screen, much like a page in a book. Anderson and Sayers suggest that even when a page on a screen is altered, it is still captured in our own sequential order-the "sedimentary layers in the material world.” Bridle (2012) mentions visual iterations of computer screens are snapshots. In turn, each visual iteration forms a snapshot - a continuation of the timeline of rhetoric from oratory to written to digital, multimodal rhetoric - as Bridle had mentioned. But Anderson and Sayers contend that because of the multimodal existence of communication, these folds become more like "fluids" (p. 82), which promotes a more sensible visualization of large amounts of data and visual information. This fluidity allows for the many convergences of technologies, software, creative processes, etc., as people write, create, save, delete, augment, rewrite, borrow and reprocess (Worsham \& Olsen, 2008). Anderson's and Sayers' interpretation gives Bridle's scholarship credence because all three scholars recognize the latest stage of digital rhetoric —-Anderson and Sayers speak of fluid rhetoric, and the New Aesthetic capitalizes on that fluidity to explain overlapping boundaries—not unlike tributaries entering a stream, which eventually ends up in the ocean. 


\section{Print and Digital Journalism}

The fluidity is influenced by crowd participation. A journalist or team of journalists report news in, for example, a written format, whether it be in print or digital format. The story is passed to the editor or editorial board to be vetted, fact-checked and proofed. Readers used to have the opportunity to write to the editor to comment on a story, and that letter may or may not have been published in the paper. Today, with the advent of digital comments sections, users can provide real-time feedback on stories and issues. This includes story releases on mediums such as Twitter, where users comment immediately, "favorite" the story if they like it, retweet to followers, or give negative feedback. Furthermore, these comments extend beyond the comments section into social media-Facebook, Twitter, Wikipedia, Reddit, Foursquare, Swarm, Snapchat, Instagram, etc.

\section{The Digital Sphere}

\section{Reshaping Space, Place and Time}

Social media platforms (and even smartphone photography) often employ GPS data that correlates to when and where media and comments were uploaded. The "geotagged data can be easily retrieved and mapped using online mapping platforms such as Google Maps and Open Street Map, as well as a growing number of ad hoc 
cartographic applications ${ }^{2}$. Caquard (2014) also mentions that geotagging reshapes what we identify as place, topography, space and community: "The cartography this collective knowledge, made of geographic layers, personal information and collective stories, contributes to the reshaping of places and communities" (p. 142). All of these changes happen smoothly and fluidly in response to the original story. The real question is how the online newspaper engages with the community beyond tracking and regulating comments.

\section{Metadata and Datamining}

Many larger online newspapers save and store metadata, massive quantities of archival data that can be broken down into a basic form, which amounts to "bean counting" that requires software, algorithms, librarians and indexers (Ridolfo \& HartDavidson, 2015, p. 105). Part of this metadata includes geotagged references. To use a librarian or indexer or other software specialist to find specific patterns or groups of information in metadata is called datamining. An alternative to using people to datamine is when software collects information, such as when you use a mobile device to read an article—for example, “ABC News would like you to share your location: yes or no?” If you select "yes," you are consenting to be monitored by your location and what you look at on the site. According to Ridolfo and Hart-Davidson, expensive software, hardware and human resources are needed to do some serious datamining (2015). A staff is needed to help build algorithms and then visualize or print out datasets. Data mining is "the

${ }^{2}$ For further reading, see Caquard, 2014. p. 141; Beauchesne, 2011; Butler, 2010; Elwood and Leszczynki, 2011; Graham and Zook, 2001; Kelly, 2013. 
process or practice of examining large collections of data in order to generate new information, typically using specialized computer software" (OED, 2015).

Because of the cost of datamining, we rarely see small and mid-sized digital newspapers utilizing this resource. But advances in public access technology, such as Google Maps, offer free (as in cost-free for use) resources that editors can use to their advantage without costly overhead, software or consultancy firms. Instead of journalists researching important but not report-worthy topics, citizen journalists are picking up the more topic- or region-specific stories that cater to a smaller audience. "Private-sector companies and citizens are now assuming some of these [reporting] responsibilities. For instance, local residents in some communities in the USA are turning into 'mapping bodies,' using handheld devices such as GPS and cell phones to collect and map data from their neighborhoods, and to report issues and crime to the local authorities" (Caquard, 2014; Wilson, 2011b).

\section{Social Collaboration}

People are collaborative beings, as exemplified by sources such as Wikipedia, Open Street Map, Reddit and online video games. Crime mapping is an important topic that many citizens may feel passionate about and would offer communal information (Bridle, 2014; Jackson, et al., 2008; Joiner, et al., 2012; Perkins 2013). This sort of feedback loop, utilizing sources such as the Chicago Tribune, is symbiotic and builds community, as well as trust with a media source. As a collaborative member of the Tribune, readers become citizen-journalists, community members, and not just linear 
spectators of sensational crime stories. They aid in the fluidity of reporting and serve as organic metadata "machines."

There are shortcomings to citizen reporting and geospatial communication from laypersons when it comes to interacting with reporters. Caquard (2014) mentions that the interaction is limited to those with technical prowess and the equipment that is used to provide geospatial and social interaction in a digital sphere. This is not unlike, he asserts, the original dominance of European settlement in the "New World" as their technology outpaced the indigenous peoples. Then, as now, technology aided in defining boundaries, economic and financial power, and investigative practices that aided proficient groups (Donohue, Tichenor, \& Olien, 1973). Citizen journalists are going to reflect the populace that can afford to have the proper equipment and wherewithal, as well as time to arrange and publish the accumulation of data (Brooke, 2009).

Daniel (2002) noted there had been little scholarship that looked at the convergence between professional journalists and rhetoricians, identifying a handful of other scholars attempting to understand the continually reinvented "postmodern public sphere" (p. 507) that responded to journalism reports and news. "Journalists in and out of the academy are concerned with encouraging public participations, bringing to life the elusive 'public(s)' of 'public affairs.' Such concerns are especially apparent in the public or civic journalism movement and its research" (p. 508). These researchers recognized that journalists were continually looking for ways to acknowledge and encourage public participation. The use of interactive crime maps could be yet another iteration of this type of participation. 
Crime reporting and citizen collaboration are meant for "watchdog" newspapers that wish to expose truths, find new data and report - in this case - criminal activity. From a quantifiable standpoint, research by Zhuang (2014) suggested that citizen journalists, overall, are actually more reliable than professional journalists when reporting catastrophes and other high-profile news in the digital sphere in comparison with longform journalism. Citizen journalists are usually on scene, there are a vast number of them and they have multimedia tools such as smart phones and cameras that can be used in print and New Media. On a credibility scale based upon citizen-reader reactions, Zhuang (2014) said that the credibility mean value of citizen journalists was higher than that of professional journalists. (p. 28). The lower the mean value, the higher the credibility and believability. The crime-reporting citizen journalists often have advantages: immediate access to the scene, smartphone or drone technology, social media, and a quick reaction to the event that preserves memory loss. The recent smartphone footage of police committing crimes on African Americans put evidence directly into the hands of consumers and investigators, which contributed to the movement called Black Lives Matter.

\section{Algorithmic Racism and Sexism}

While one of the attractive properties of the New Aesthetic is that often the unexpected occurs, there are a few expected outcomes. As a case study, the digital mapping system Open Street Map, which is used by large applications such as FourSquare, Flickr and Craigslist, is crowd-sourced - it is developed and built by users in the same vein as Wikipedia. Other users might correct improper directions or add new 
businesses. However, Open Street Map is predominantly upgraded and augmented by adult, white males (Plummer-Fernandez, 2014; Bridle, 2014; Jackson, et al., 2008; Joiner, et al., 2012; Perkins 2013), even through many females use the application to navigate and find locations. But because males build locations via application, they tend to concentrate on traditional male-oriented locations, such as sports bars, auto dealerships and technology-related businesses like the Apple Store. Women, however, traditionally look for boutiques, children's clothing stores and restaurants like those that specialize in smoothies and yogurt, or for children (Bridle 2014). Women, therefore, have a difficult time finding locations they want when dealing with a male-coded application. The same issue relates to sexuality, religion, politics and race, to name a few. When discrimination passes along from human to code to human, the nomenclatures of gender and race discrimination are loosely known as algo-sexism and algo-racism. It is expected that there will be manifestations of algo-racism, in particular, and possibly algo-sexism and gendered issues. $^{3}$

${ }^{3}$ For further reading on how gender and race affect algorithmic rhetoric, particularly through OpenStreetMap and digital cartography rhetoric, see: Beauchesne, 2011; Butler, 2010; Caquard, 2014; Elwood and Leszczynki, 2011; Graham and Zook, 2001; Jackson, et al., 2008; Kelly, 2013; Joiner, et al., 2012; Perkins 2013; McConchie 2015; Schwartz 2014) 


\section{RESEARCH QUESTIONS}

Given the New Aesthetic definition of a glitch as errata that occur as part of a complex system of competing technologies, billions of lines of conflicting code, and new machines, we can look to various overlaps in maps, crime reporting, and human cognition to determine ruptures in the system. These ruptures serve as identifying markers for innovation and discovery. Therefore, this thesis proposal asks the following research question:

RQ1: What glitches are present in the overlap between print and digital crime reporting when considering the overlaps between maps and crime reporting from The Chicago Tribune and Crime Reports? 


\section{METHODOLOGY}

Methods used are visual analysis and digital rhetoric analysis of New Media maps. The sample consists of one month of online crime reporting from the Chicago Tribune-from August 1 to September 1, 2016. This time period was chosen during the transition period of, historically, the most violent time period in Chicago (summer) and a more "average" period when public school resumes. This time period also encapsulates baseball season in Wrigleyville neighborhoods. This is to help tease out any data that might demonstrate the effect schooling, childcare access and school closures might have. Three different settlements will be investigated. Three communities in three geographic areas were chosen: "South Side": New City, West Englewood, and Englewood; "West Side": Humboldt Park, West Garfield, and East Garfield; "Wrigleyville”: Lake View, Uptown, and Lincoln Park. These areas were selected because of their concentration of crime, different backgrounds and history, and differing locations within the city limits. Crimes reported from the Tribune were plotted onto Google Maps to form a crime map that was cross-referenced with Crime Reports data during the same period. Following time-tested crime mapping theory, all recorded crimes from the Tribune and Crime Reports were examined from the vantage point of hotspot theory, cluster theory, macro level research, and micro level research.

When examining basic data plots, two levels were used in order to discern differences between crime plotting theory and New Aesthetic theory. These levels are defined as macro- and micro-level data. As noted in Paynich and Hill's 2010 assessment of "hot spots," clusters of crime form macro-level data plots, and they are easily assessed visually. Although the literature about the definition and criteria of hot spots is varied, 
Paynich and Hill found that hot spots are often phenomena-based. They noted Martin, Barnes and Britt's (1998) study on arson hot spots in Detroit, which used a GIS map to map "current arson hot spots and abandoned buildings that may become future targets" (p. 194). As a result of the research and studies on preventive measures, several hot spots were eliminated and there were fewer fires. Some "stubborn" hot spots were not eliminated, but researchers and city officials noted that those areas were "situated in areas of high crime and a large number of abandoned buildings, a low level of community organization, and high levels of poverty" (p. 194). In effect, experts say that there were limits to arson prevention in areas that offered little collaborative support or resources to fire crews already stretched thin by scant government finances.

Additionally, what is not there - from a position of missing data or confusing data - fulfills a criterion of Glitch Theory (Lilly, 2015) used to understand overlapping layers of technology and human interaction. In addition, Glitch Theory focuses on anomalous or errant data. Using Kelly's (2013) and Paynich and Hill's (2010) bodies of work, crimemapping theories were attached to the New Aesthetic framework of querying the differences in reporting from both sources. One example is of Paynich and Hill's observation of the proximity of schools in relation to registered sex offenders (2010). Mayor Rahm Emanuel of Chicago consolidated many schools in crime-ridden districts (Perez, Jr. 2015), and, theoretically, the shuttering of schools would allow for more sexual offenders and predators to move into communities that are not in close proximities to schools. Crime Reports showed the names and locations of sexual offenders, the Tribune listed the consolidating and shuttering of schools (Perez, Jr. 2015), and Google Maps helped pinpoint the map locations of the schools. The forced overlap combination 
showed whether or not there is significant sexual offender activity in areas where schools formerly existed. There are others that consider alderman districts, race, education, religion, white collar crime, and police response times, to name a few. Some of the current maps that contain scholarly or raw data that represent the above topics helped discover data overlaps and assisted in asking secondary questions. For example, where are there violent crimes, and what factors appear with violent crimes (race, gentrification, class, religion, lack of public access to parks or education, lack of entertainment, proximity to alcohol or drugs, gang culture, etc.)? Corroborating different types of data with criminal activity is important. Journalists attempt to do this, but they typically look at past reports and evidence and corroborate and contrast the evidence with testimonials and interviews.

\section{Selection of City}

Chicago was selected because of access to crime reports in both the Tribune and Crime Reports. The city proper has a serious issue with violent crime that is continually reported on, yet all rhetoric points toward no definitive answer or confluence of answers to the exploding crime rate. Chicago is the third-largest city in the United States $(2.7$ million) that is home to large populations of Caucasian, African-American and Latino populations as well as robust populations of those identifying as Polish, Russian, Ukranian, Arab, Greek, Irish, German, Mexican, Guatemalan, and French (U.S. Census Bureau, 2014). Additionally, there are many religions sharing the same area, including Christians, Jews and Muslims. Chicago has also been a historic destination to African Americans that fled the South and Jim Crow laws during the Black Exodus of the $20^{\text {th }}$ 
century, and is self-determining to be a "sanctuary city" for immigrants during President Trump's administration.

The comparison between the data from the Chicago Tribune and Crime Reports are considered as New Aesthetic overlaps, as there are three or more overlapping data sources. The overlaps demonstrate the differences between crimes reported by police forces and crimes reported by the Chicago Tribune. Visual analysis was used to find obvious differences in the data by comparing the Crime Reports map with the personal, plotted Google Maps (fig. 4; fig. 5).

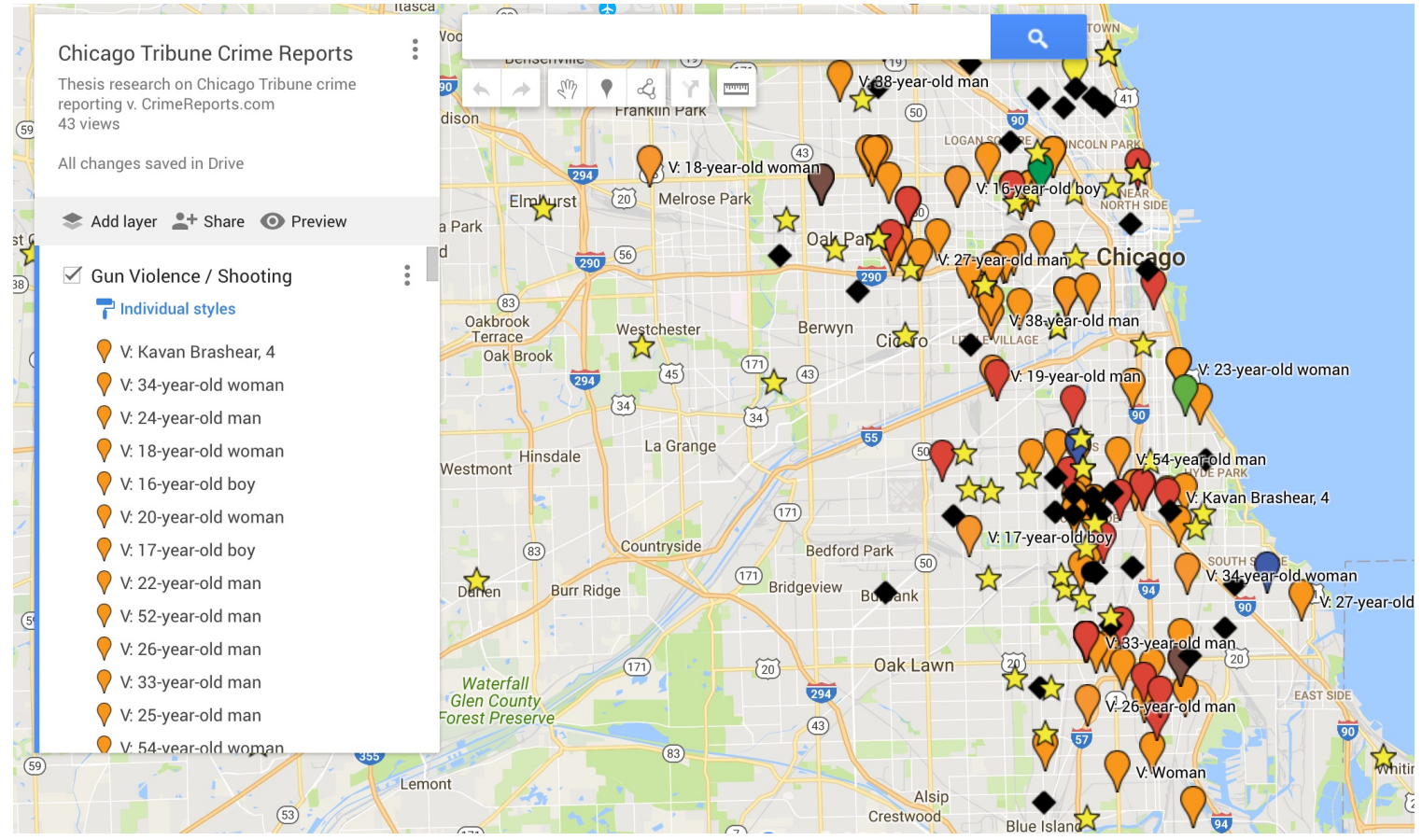

Figure 4. Two-day sample of The Chicago Tribune's crime reporting data, plotted onto Google Maps 


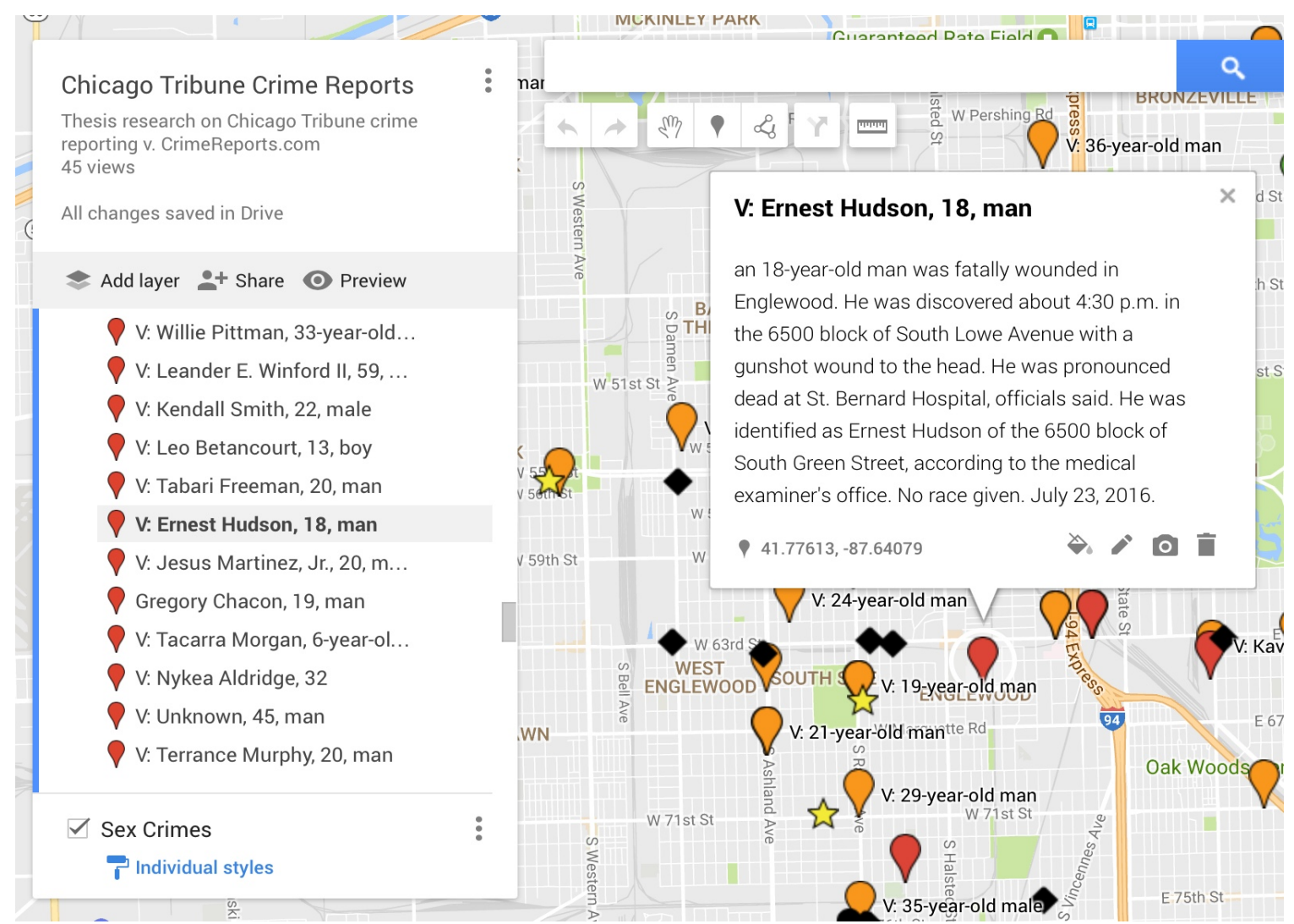

Figure 5. Chicago Tribune's crime reporting data, plotted onto Google Maps; with brief detail on one specific crime after clicking on one of the pins

Paynich and Hill (2010) explain an example of crime reporting and visual analysis in detail when they refer to "hot spots," which are "small geographic areas that experience higher than average levels of crime for a consistent period of time" (p. 193). A digital rhetoric analysis of New Media maps will use previous research and theory to explain new phenomena. For example, according to Paynich and Hill (2010), “An analyst may also want to query incidents that are within a distance of ... point data, such as schools, liquor establishments, or pawn shops" (p. 342) (fig. 6). 
Distance Analyses

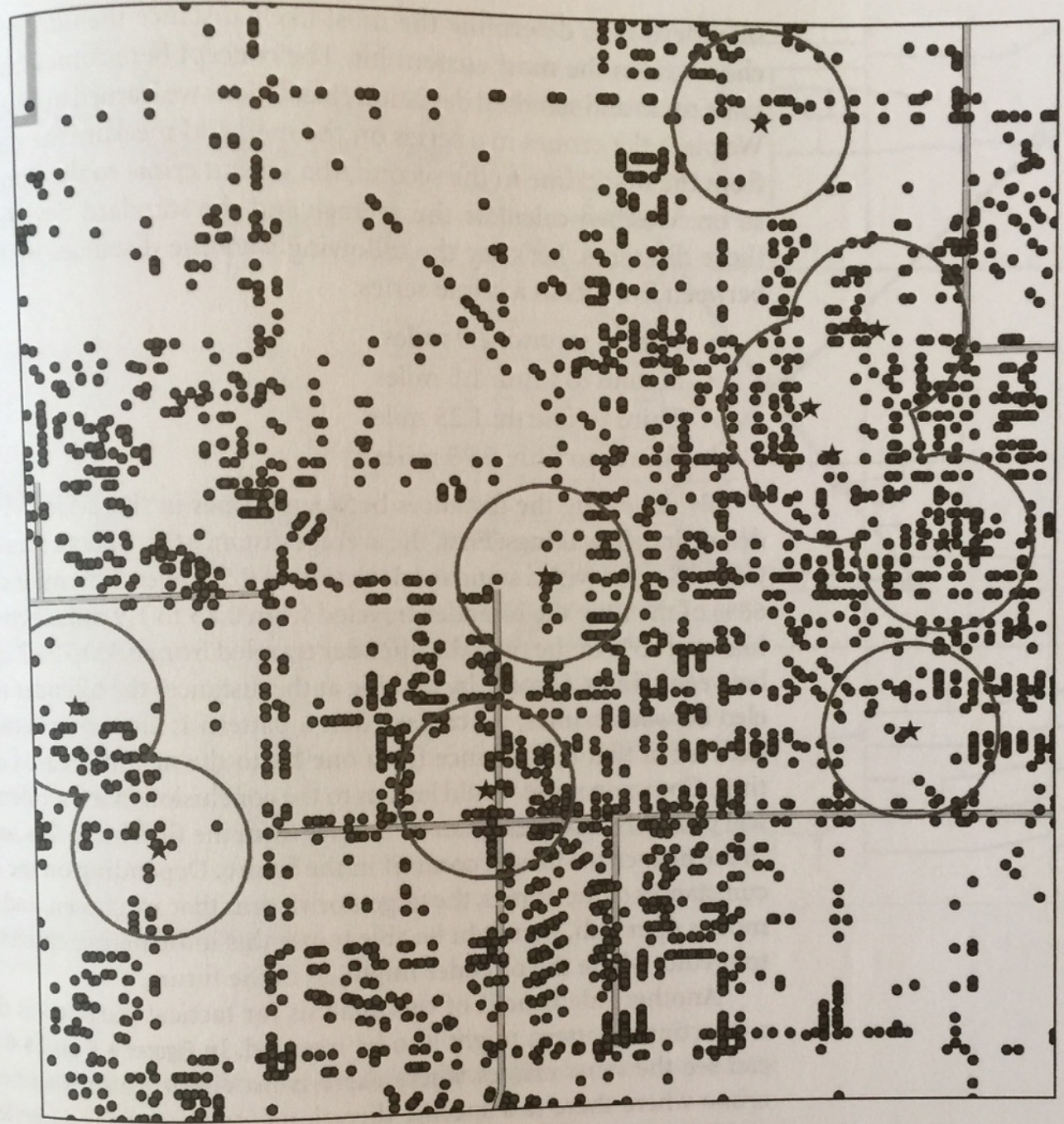

Legend

$\square$ Buffer_of_AREA_SCHOOLS

- OfFEnSE_dATA

* area_schools

Figure $9-4 \quad 1000$-foot Buffer of Glendale Schools
Source. Arcolis

Figure 6. 1000-foot Buffer of Glendale Schools. A distance analysis of crime plots and area schools of Glendale, AZ (Paynich \& Hill, 2010, p. 343) 


\section{Selection of Neighborhoods}

Although there are 77 defined community areas (Spencer, 2013; City of Chicago, 2016) and over 200 anecdotally named neighborhoods (City of Chicago, 2016), three groupings were chosen to fit the scope of this research because they represent substantial, geographic areas that are sizable, crime-ridden with a variety of issues, and differ from each other in history, race and class. Wrigleyville, the area that surrounds Wrigley Field, home of the Chicago Cubs Major League Baseball team (communities of Uptown, Lakeview and Lincoln Park), is predominantly white, younger, and middle class. The anecdotally named Back of the Yards/South Side (communities recognized as Englewood, West Englewood and New City) is a mix of African-American Chicagoans, whites and Latinos caught in the flux of gentrification, rapid increases and decreases in real estate prices, and fast changes in educational and grocery accessibility. The community conglomeration of East- and West Garfield and Humboldt Park appears to be a response to the gentrification migration of African Americans and impoverished inner city Chicagoans that fled South Side neighborhoods in search of accessible rent. These latter neighborhoods, collectively recognized as West Side Chicago, contain some of the most dense violent crime statistics and appear to suffer the most from school closures and the absence of employment and small businesses.

However, the point of the New Aesthetic is to not only take into account the obvious differences in overlapping data, such as the aforementioned "hot spots," but also to examine other data such as the proximity of parks; the proximity to bodies of water; the absence or presence of grocery stores; alderman district boundaries; locations of drug rehabilitation and methadone clinics; school performance ratings and rankings, 
gentrification; gang territory; the presence of entertainment or exercise facilities, gayfriendly neighborhoods, etc. Zillow, the real estate application that uses massive algorithms, has predicted gentrification by noting the opening of a new Starbucks coffee business (NPR.org, 2016).

These methods serve as a measure of crime reporting by the Chicago Tribune by exploring sensationalism, race, gender, geography, police districts, and proximity to the Tribune.

Crime Reports takes actual police blotter and reported data, categorizes them and uses an icon to demarcate the city block/general location, date and nature of the crime where the crime occurred. The data is much more plentiful and stout than news reporting but lacks the reporting element or context.

\section{Types of Crimes}

The crimes that will be examined, and color-coded on Google Maps are:

1. Homicide

2. Robbery (strong arm; with weapon or without)

3. Burglary

4. Vehicle theft

5. Theft from vehicle

6. [6a. and 6b.] Assault (with weapon and without)

7. Assault (sexual)

8. Theft over $\$ 500$

9. Theft under $\$ 500$ 
10. Miscellany: trespassing, fraud, domestic violence, and all other crimes not included in numbers $1-9$., etc. This category is not meant to be overlooked or lumped together, but must be acknowledged for the sake of data collection and future dialogue. This collective category is also not intended to minimize the severity of the crimes.

The listed crimes are numbered to prevent confusion and to create a hierarchy of the perceived severity. A homicide is punished more severely than a burglary, for example. The implications of severity have consequences that include prison, morality, neighborhood safety, property values, etc. Also, by dividing crimes by number, color or icon, we can see on a map a rapid assessment of the distribution of crimes.

A one-month sample of data is enough to establish the most significant patterns (Lipshultz \& Hilt, 2002). The month studied was the last full month of summer in 2016, when crime is most active in Chicago during good weather, during the partial absence of a school term, and during a deficit of personal resources in the heat (Jerpi, 2011). Chicago has many diverse neighborhoods that include Hispanic, Polish, Russian, African-American, Caucasian, Vietnamese, Hmong, and Jewish communities, to name a few. Each ethnic group has a variety of reasons for relocating to Chicago. In the case of African Americans, one major reason for a large population is due to the First and Second Great Migrations, or Black Exodus, during the diaspora of the descendants of slaves, freedmen and former slaves from the Deep South and Jim Crow laws, and the freedom from violence and unjust persecution. This offers insight to the complexity that might aid New Aesthetic observations. The cultural groups form communities, political groups, gangs, and cross-cultural mixing. To date, the only map created by the Chicago Tribune 
that includes race or culture consists of plots that denote African American, White, and Hispanic populations.

\section{Publications}

Crimereports.com (also referred to as Crime Reports) is a comprehensive, visual and interactive database that is free to the public, and provides a variety of basic metrics and analytics that allow anyone with access to the Internet to search criminal occurrences in any participating city. Although the citizenry does not report all crime, this website serves as a generalized marker of all reported criminal activity. Additionally, because of the difficulty in identifying many races - Crime Reports often does not report races or genders - this research did not concentrate on race, but left open future endeavors to examine race as another aspect of New Aesthetic chronicling or Glitch Theory research. 


\section{FINDINGS}

\section{Macro and Micro Viewpoint}

A summary visual examination (macro level) shows where clusters of crime are occurring. No shape or shaped tool (circle, ellipsis, etc.) was used to discern or group clusters of crime, as shapes often do not match hot spot clusters (Paynich and Hill, 2010). Instead, a visual analysis determined groups of crime after they have been plotted. This visual analysis also took into account proximity of other crimes, the lack of crime, clusters of similar crime, and phenomena-based patterns. The two types of macro viewpoints consider crime clusters on: 1) Crime Reports and 2) the Google Map of Chicago Tribune crime reporting. There are also two types of micro viewpoints that are consider crime clusters on Crime Reports and, to a lesser extent, the Google Map of Chicago Tribune crime reporting.

On Crime Reports, all crime clusters are of reported crime, as logged by the Chicago Police Department (CPD). Each crime detail provides an abundance of information, such as: location (street and block); type of crime; designation of crime (property, quality of life, or violent); time; locations (sidewalk, house, vacant lot, vehicle, etc.); whether an arrest was made; reporting agency; incident number; case number; and other qualifying identifiers, such as type of narcotic (cannabis, synthetic opioid, white heroin, etc.). However, users of the website can use neighborhood boundary lines (usually roads, parks and tributaries), as denoted by the City of Chicago's official neighborhood map, to track larger numbers of crime from a more distant cartographic level. This method was used to determine the volume of violent crime, property crime, and quality of life crime to ascertain differences in communities (Tables 1a, 1b, 1c). 
Table 1a: Comparison of West Side community crime

\begin{tabular}{lllll}
\hline Description & W. Garfield & E. Garfield & Humboldt Prk & Total \\
\hline Violent & 271 & 250 & 262 & 783 \\
Property & 190 & 223 & 256 & 669 \\
QoL & 116 & 69 & 83 & 268 \\
\hline
\end{tabular}

Table 1b: Comparison of South Side community crime

\begin{tabular}{lllll}
\hline Description & W. Englewood & Englewood & New City & Total \\
\hline Violent & 347 & 304 & 250 & 901 \\
Property & 378 & 331 & 343 & 1052 \\
QoL & 37 & 21 & 21 & 79 \\
\hline
\end{tabular}

Table 1c: Comparison of Wrigleyville community crime

\begin{tabular}{lllll}
\hline Description & Uptown & Lake View & Lincoln Park & Total \\
\hline Violent & 148 & 147 & 145 & 440 \\
Property & 337 & 534 & 485 & 1356 \\
QoL & 10 & 10 & 10 & 30 \\
\hline
\end{tabular}

The first macro-level data collected were cumulative numbers over the period of Aug. 1, 2016 to Sept. 1, 2016 in three differing neighborhoods of three sections of the city, as defined in the methodology. Then, as displayed in charts $1-3$, the crimes were broken down into quantity and type of crime (violent, property, and quality of life) per neighborhood, and displayed in neighborhood clusters selected prior to data collection. There are three regional areas: 1) The "Wrigleyville" area-Uptown, Lakeview, and Lincoln Park; 2) "South Side" Chicago_-West Englewood, Englewood, and New City; and 3) "West Side" Chicago—East Garfield, West Garfield and Humboldt Park.

\section{Initial Findings}

By using public census data grouped by Chicago neighborhood, a simple formula was devised to take population and land area to corroborate population density data from 
the 2000 U.S. Census and then take Crime Reports data from Aug. 1 - Sept. 1, 2016 to calculate crime density for that time period. According to data, the selected neighborhoods from West Chicago were the most crime-ridden, with one crime for every 58 residents. South Chicago's selected neighborhoods had one crime for every 68 residents. The Wrigleyville neighborhoods had one crime for every 122 persons (tables $1 a-1 c)$

Each area had a different emphasis on type of crime when examining the macro level of three categories of crime: violent, property, and quality of life. West Chicago and South Chicago had 901 violent crimes, and they each had a similar number of property crimes. However, West Chicago had a disproportionate amount of quality of life crimes (268). South Chicago had 79 reported quality of life crimes. According to Crime Reports, quality of life crimes consist of drug use, possession, and sale; prostitution; disorderly conduct; and obstruction (tables $2 a-2 c)$.

Wrigleyville, on the northeast side of Chicago's downtown epicenter, experienced about half the amount of violent crimes but overwhelmingly led the three regions with 1,356 property crimes (table 3$)$, compared to South Chicago $(1,052)$ and West Chicago (669). Crime Reports defines a property crime as criminal damage to property or criminal damage to vehicle; theft $(>\$ 500)$, and theft $(<\$ 500)$; retail theft; breaking and entering; burglary; vehicle theft; and theft from a boat or watercraft.

From this perspective, an examination can be drawn on the apparent highlights of elevated crime, as well as the absence of crime. An analysis of macro data suggests a need to explore why there are elevated property crimes in Wrigleyville, elevated quality of life crimes in West Chicago, and elevated violent crimes in South Chicago. 
Additionally, why did West Chicago experience a 1:58 ratio of crime per persons (crime density) for one month, even though its population density is roughly similar to that, or less, of South Chicago (12,363 persons per square mile compared against 15,802 persons per square mile, respectively)?

Demographics Tables, by region and regions' selected neighborhoods:

Table 2a: U.S. Census data on selected Chicago neighborhoods (2010).

\begin{tabular}{lll}
\hline South Chicago & Pop. 2010 & Area (Sq. Mi.) \\
\hline Englewood & 40,222 & 3.1 \\
W. Englewood & 45,282 & 3.1 \\
New City & 51,721 & 4.8 \\
Total Pop. & 137,225 & \\
Total Area & & 11.1 \\
Pop. Density & $12,363 /$ sq. mi. & \\
Violent Crimes & 901 & \\
Prop. Crimes & 1,052 & \\
QOL Crimes & 79 & \\
Crime Density & 1 per 68 ppl \\
\hline
\end{tabular}

Table 2b: U.S. Census data on selected Chicago neighborhoods (2010).

\begin{tabular}{lll}
\hline West Chicago & Pop. 2010 & Area (Sq. Mi.) \\
\hline E. Garfield & 20,991 & 1.9 \\
W. Garfield & 23,019 & 1.3 \\
Humboldt P. & 65,836 & 3.6 \\
Total Pop. & 107,451 & \\
Total Area & & 6.8 \\
Pop. Density & $15,802 /$ sq. mi. & \\
Violent Crimes & 901 & \\
Prop. Crimes & 669 & \\
QOL Crimes & 268 & \\
Crime Density & 1 per 58 ppl \\
\hline
\end{tabular}

Table 2c: U.S. Census data on selected Chicago neighborhoods (2010).

\begin{tabular}{lll}
\hline Wrigleyville & Pop. 2010 & Area (Sq. Mi.) \\
\hline Lakeview & 94,817 & 3.1 \\
Lincoln Park & 64,320 & 3.2 \\
Uptown & 63,551 & 3.2 \\
Total Pop. & 222,688 & \\
Total Area & & 9.5 \\
Pop. Density & 23,440/sq. mi. & \\
Violent Crimes & 440 & \\
\hline
\end{tabular}




\begin{tabular}{ll}
\hline Prop. Crimes & 1,356 \\
QOL Crimes & 30 \\
Crime Density & 1 per $122 \mathrm{ppl}$ \\
\hline
\end{tabular}

\section{Micro Viewpoint}

\section{Crime Reports}

On a micro level, several areas were identified that corroborated crime research, hot spot theory, and other areas of visual interest: schools, gang territory, quality of life crimes, drug activity, prostitution, arson and sex offenders. Criminologists, sociologists, and data scientists look for landmarks and landscape artifacts that bring together people, cultures and events in different ways (Weisburd, Bernasco, and Bruinsma, 2009; Paynich and Hill, 2010; McGloin, Sullivan, and Kennedy, 2012). As referenced earlier, schools offer conflicting changes in crime patterns, as they both collect large groups of people, yet they also, overall, serve as crime buffer zones (Henderson and Lowell, 2000; Paynich and Hill, 2010). Gangs and gang territories overlap in some areas, causing friction and violence. However, research has shown that many gang-ridden neighborhoods "selfpolice" and may reduce crime, overall (Paynich and Hill, 2010). Other point data, such as quality of life crime - used in Crime Reports as yellow tabs that demarcate nonviolent, non-property crime - and sex offender addresses, augment hot spot theory and glitch theory for purposes of understanding crime patterns.

\section{Schools}

Using previous research by Reno (1998), Hendersen and Lowell (2000), and Roncek (2000), this analysis based one of the micro viewpoints on the perspective of 
public and private schools and their relationships with crime or a lack of crime. Chicago experienced a massive school closure program in 2013, when Mayor Rahm Emmanuel proposed the shuttering of 48 elementary schools and one high school program as an effort to combat a "massive budget deficit" (Ahmed-Ullah, Chase, \& Specter, 2013). The result saw many school buildings become "shells" or unoccupied structures. Research is divided on the role schools play in crime statistics. This study examined 24 schools and the surrounding crime during Aug. 1 - Sept. 1, 2016. Eight schools were chosen at random in the three analyzed regions (West Chicago, South Chicago, and Wrigleyville), Additionally, four shuttered schools (two from West Chicago and two from South Chicago) were examined.

Overall, there was a marked absence in crime in 20 out of 24 of the schools in the surrounding four blocks of area. The exceptions included three shootings outside of two schools in West Chicago, one homicide in West Chicago, and a variety of quality of life crimes (drug use and distribution), as well as a series of simple and aggravated assaults. An initial observation of time frames showed that a large majority of crimes occurred during school hours, particularly in West Chicago. This aligns with research by Reno (2003), who identified daytime crime surrounding schools and found that high truancy rates correlated with localized crime, particularly around high schools. When police targeted these daytime crimes, burglaries were reduced by $67 \%$ and truancies were greatly reduced. Roncek's (2000) research on crime frequency demonstrated that schools generally acted as buffer zones to crime, but that crime activity varied between schools in New York. This analysis on Chicago crime and its schools echoes his evidence and findings (fig. 7-8). 


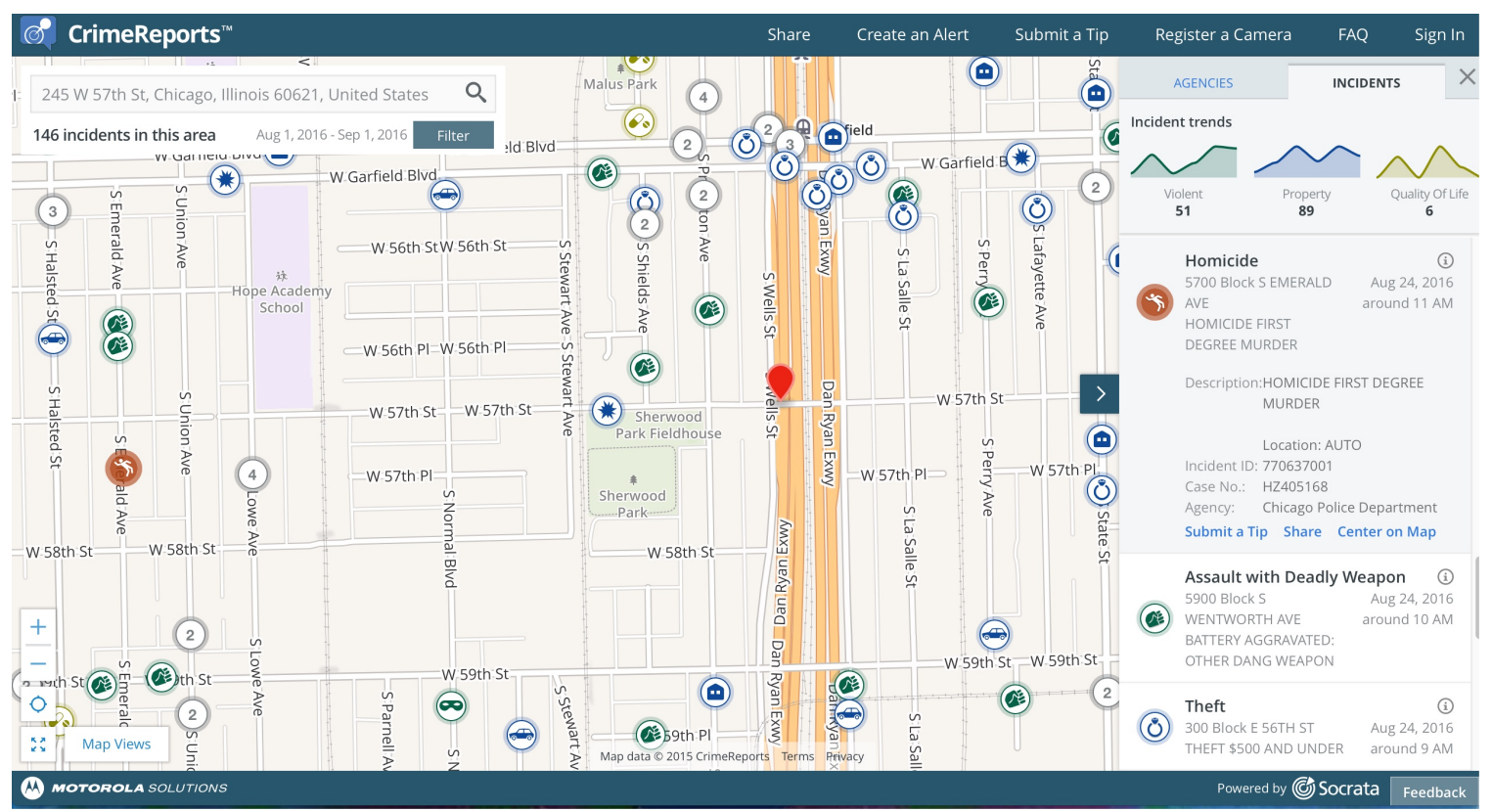

Figure 7: Hope Academy School crime buffer. Hope Academy, the purple shaded box on the left side of the image, clearly shows a largely crime-free area. Violent crimes are in green; quality of life crimes are yellow; property crimes are blue; neutral colors with a number (ex: "2") are tight clusters of crime. Hope Academy has two property crimes to the north, two assaults to the west, and a cluster of four crimes (two property, two assault) to the south. The majority of crimes lie outside of the "hot spot buffer" of at least two blocks from the school.

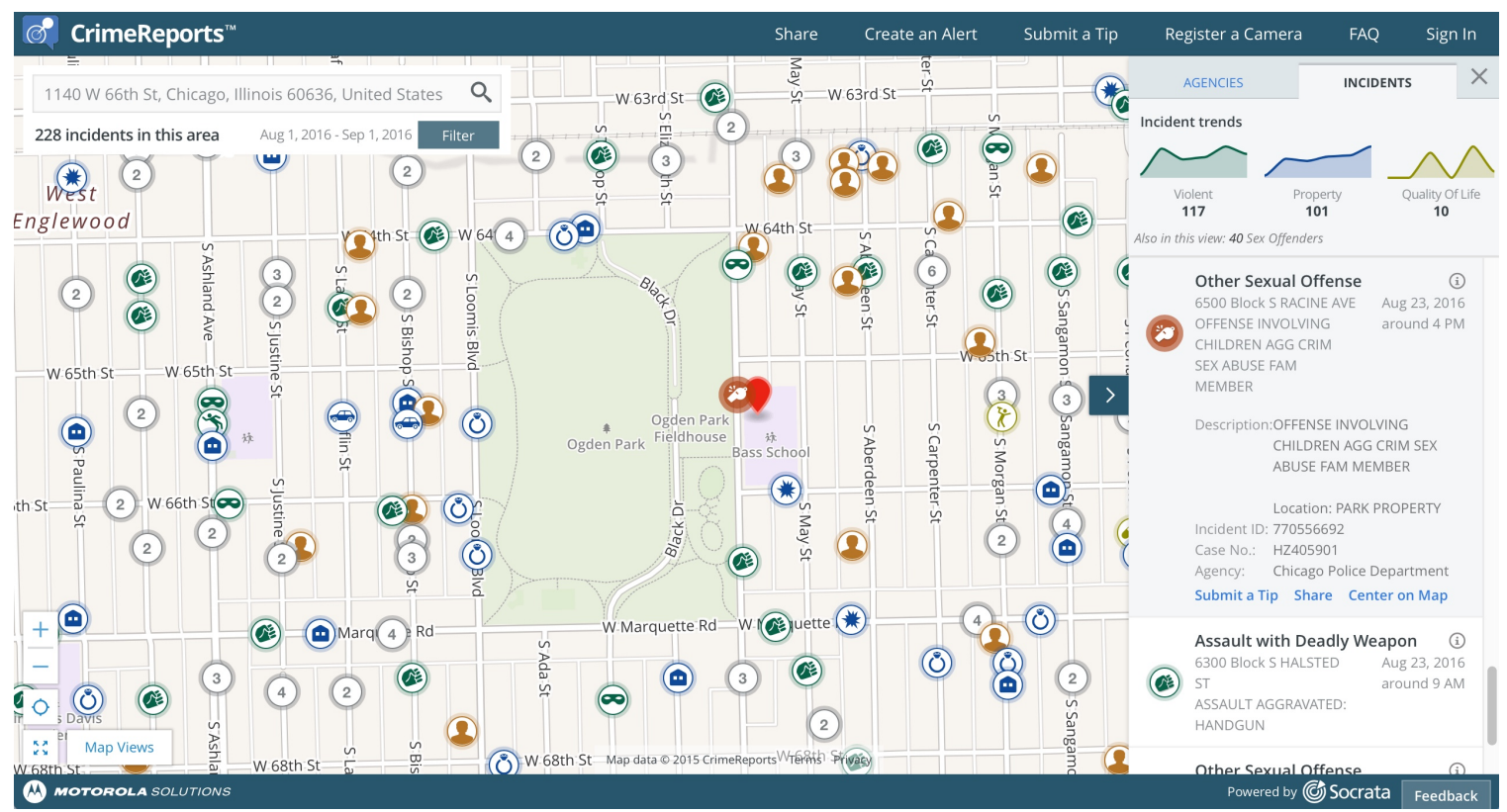

Figure 8. Bass Elementary School crime buffer. Violent crimes are represented in green; quality of life crimes in yellow; and property crimes in blue. Sex offenders are orange silhouettes of people. Bass Elementary is the purple shaded area adjacent to the east side of Ogden Park (shaded green area). Although there are many crimes in this map snapshot, there are significantly less crimes in the immediate area surrounding Bass Elementary. There are three assaults, overall, one burglary, and one theft. Also of note is one sexual offense, listed as sexual child abuse by a family member. This was most likely reported by the school as part of their mandate, or a family member sexually assaulted a child on the school grounds. 
Schools that were shuttered under the massive school reorganization plan ushered forward by Mayor Rahm Emmanuel no longer acted as crime buffers, which also echoed Roncek's (2000) research. Benjamin Banneker Elementary was closed with dozens of other elementary schools in 2013-2015. Today its neighborhood is riddled with violent, property, and quality of life crime (fig. 9); Banneker Elementary is the purple box just to the west of South Green St., and on Marquette St.

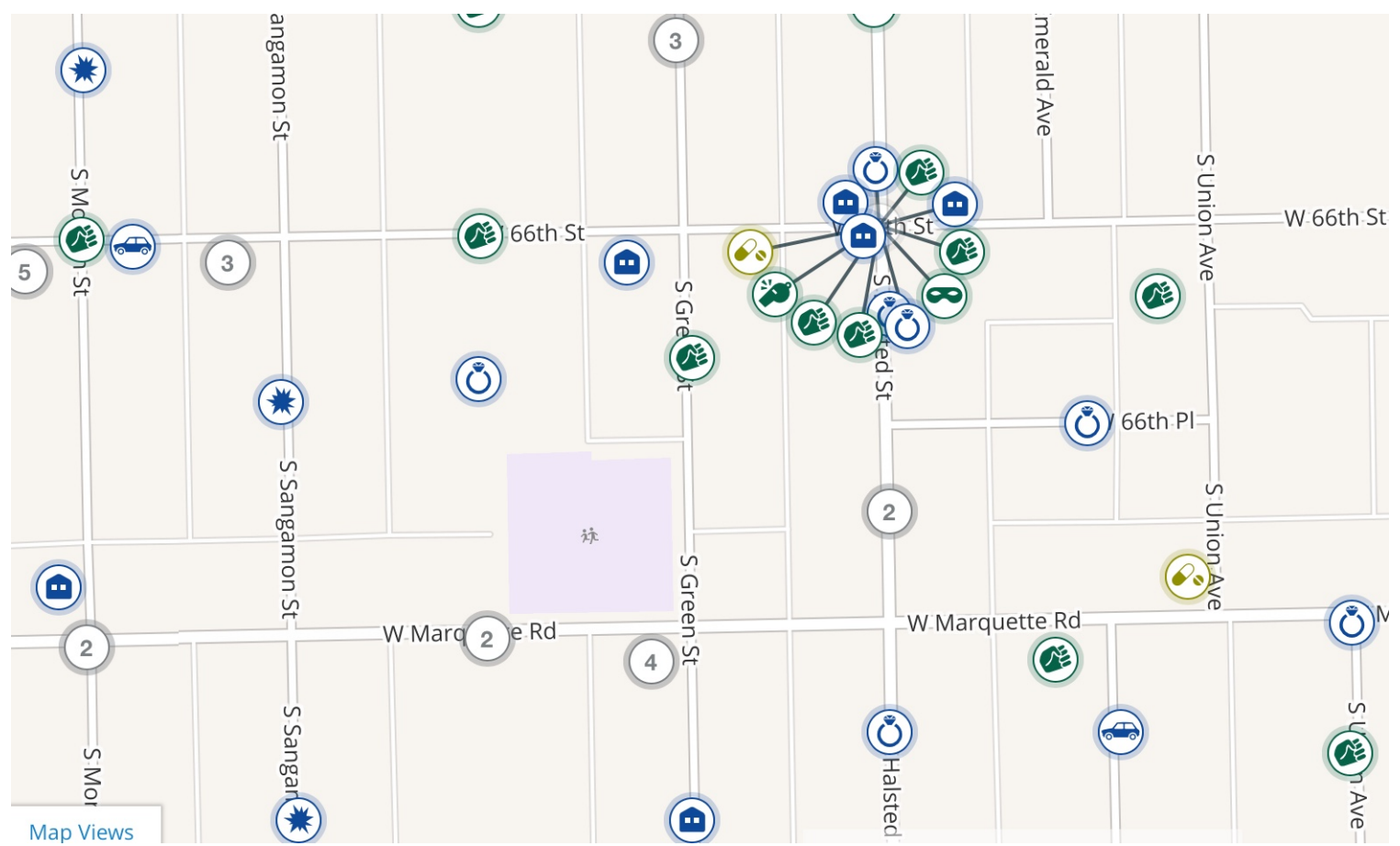

Figure 9. Loss of Benjamin Banneker crime buffer. Violent crimes are represented as green; quality of life crime is yellow; and property crime is blue. Neutral circles with a number represent a cluster of crimes at the same block or address. The purple shaded area is the now-shuttered Benjamin Banneker Elementary. Immediately surrounding Banneker There are 28 crimes within the former school's buffer zone, indicating that crime is rampant in the area. There are drug crimes, violent offenses ranging from gun violence to assaults, sexual offenses, theft, burglary, and robbery, indicating that the issue is systemic.

\section{Gang Territory}

There are two types of gang activity that are recognized in this research:

traditional gangs, with overarching philosophies that unite several factions (ex: Vice Lords, Mickey Cobras, Black P Stones), and micro gangs, which are broken up by 
localized areas, and who are becoming increasingly independent from one another with the advent of social media. Their territories were identified through a combination of YouTube drill rap videos of Chicago (2016), Twitter accounts featuring gang members and drill rappers (2016), and an interactive Google Map of gang territories from ChicagoGangs.org (2014) (fig. 10). An examination of boundary crossovers exhibited a rise in crime listed on Crime Reports (fig. 11). Several instances of heavier crime activity, particularly regarding assaults, shootings, burglary and robbery, were present in South Side and West Side neighborhoods. The most significant observation of crime along gang territory boundaries was evident in West Englewood along a large group of Gangster Disciples and Almighty P Stones, who collided along the corridor of South Ashland Avenue, and within two blocks. The amount of crime consisted of 40 out of 167 recorded crimes on the designated map (fig. 11) for the month of August 2016. Data cannot confirm whether or not the crime was gang-related, but the Tribune could investigate as part of their crime coverage. 


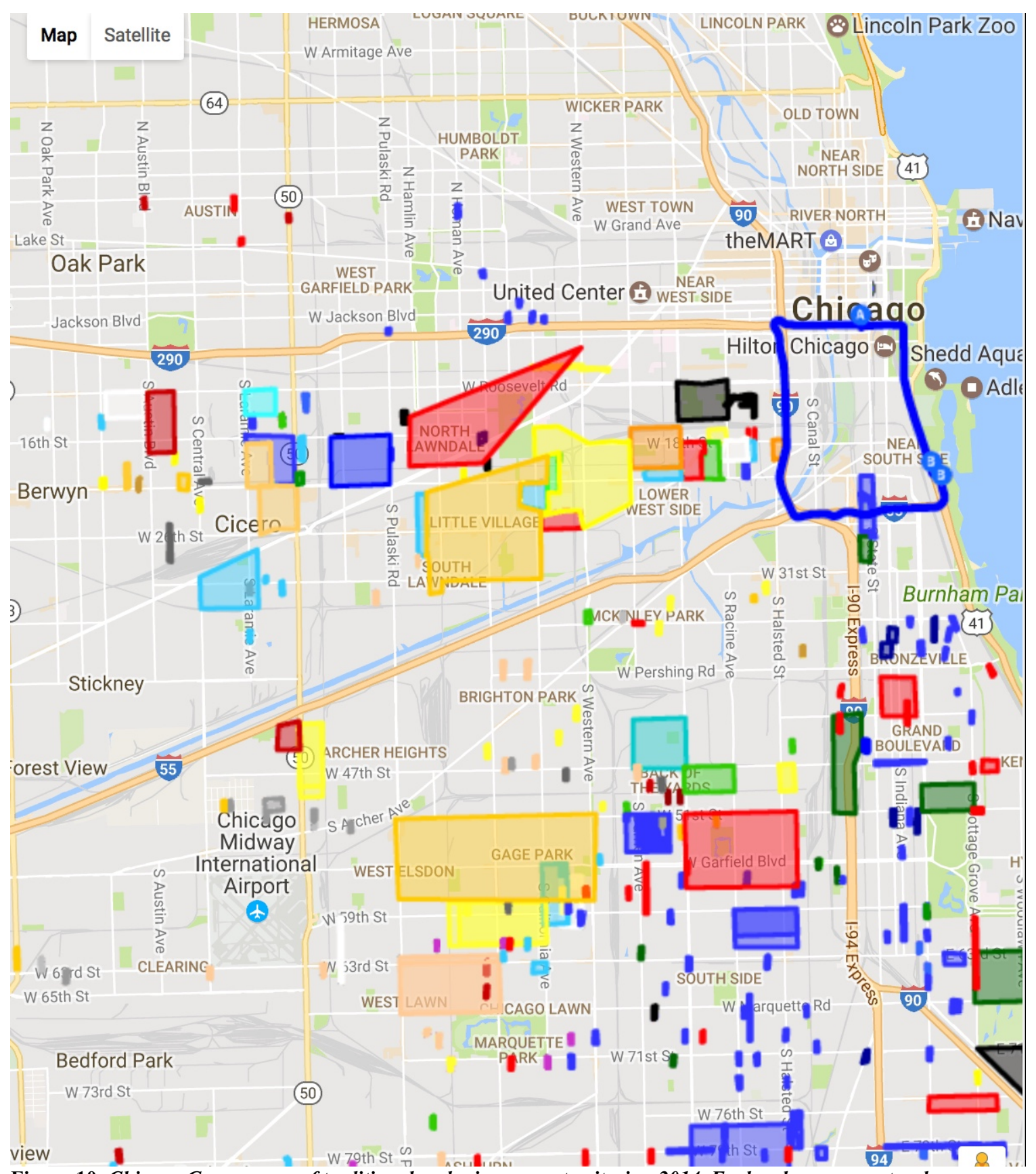

Figure 10. Chicago Gangs maps of traditional and micro gang territories, 2014. Each color represents a larger "parent" gang with overarching history or philosophy, and tied together by name; i.e., Mickey Cobras, Black P Stones, Gansta Disciples. 


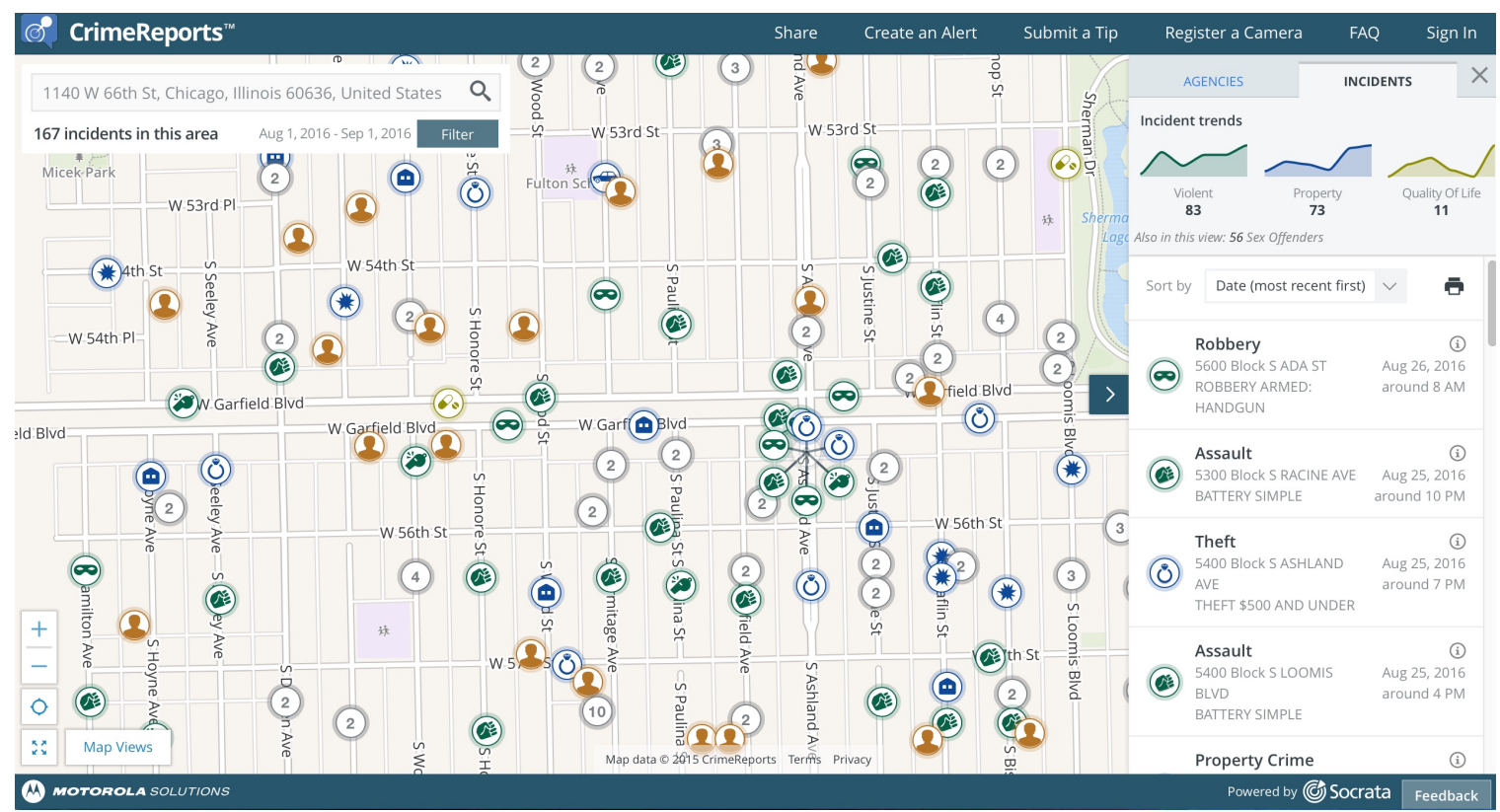

Figure 11. Gang Crossover Crime in Englewood. The cluster of crime (center-right) lies along overlapping gang boundaries at South Ashland Avenue, which runs north to south. This boundary sees a convergence of two sizable gangs: the Almighty P Stones and Gangster Disciples. Green icons represent violent crime; quality of life crime is yellow; property crime is blue; and sex offenders appear as orange silhouettes of people. The circles with numbers represent the number of crimes located on that block or address. Here, there is a large cluster of violent crime along the gang territory border. There is also a lack of drug crime (quality of life crime), which may signal no apparent drug territory under control at the boundary.

\section{Quality of Life}

As mentioned previously, quality of life crimes on Crime Reports consist of drug use, possession, and sale; prostitution; disorderly conduct; and obstruction. From the macro level of examination, West Side had more of quality of life crimes than the other two studied regions. Within West Side Chicago, the quality of life crimes were spread across three communities: West Garfield, East Garfield, and Humboldt Park. West Garfield had the most quality of life crime with 116 instances out of a total of 577 total reported crimes (20.12\% or 1:5 ratio). Humboldt Park had the second-most quality of life crime, with 83 out of 601 crimes (13.81\% or 1:7). East Garfield had the third-most quality of life crime with 69 out of 542 crimes (7.85\% or roughly 1:13). West Garfield had centers of significant clusters of quality of life crime, or hot spots, as did Humboldt 
Park (figs. 12-13). By comparison, the six communities of the three other regions had between 10 and 37 quality of life crimes during the same period (charts 1-3), and were ranked 4-9 after all examined West Side communities. 


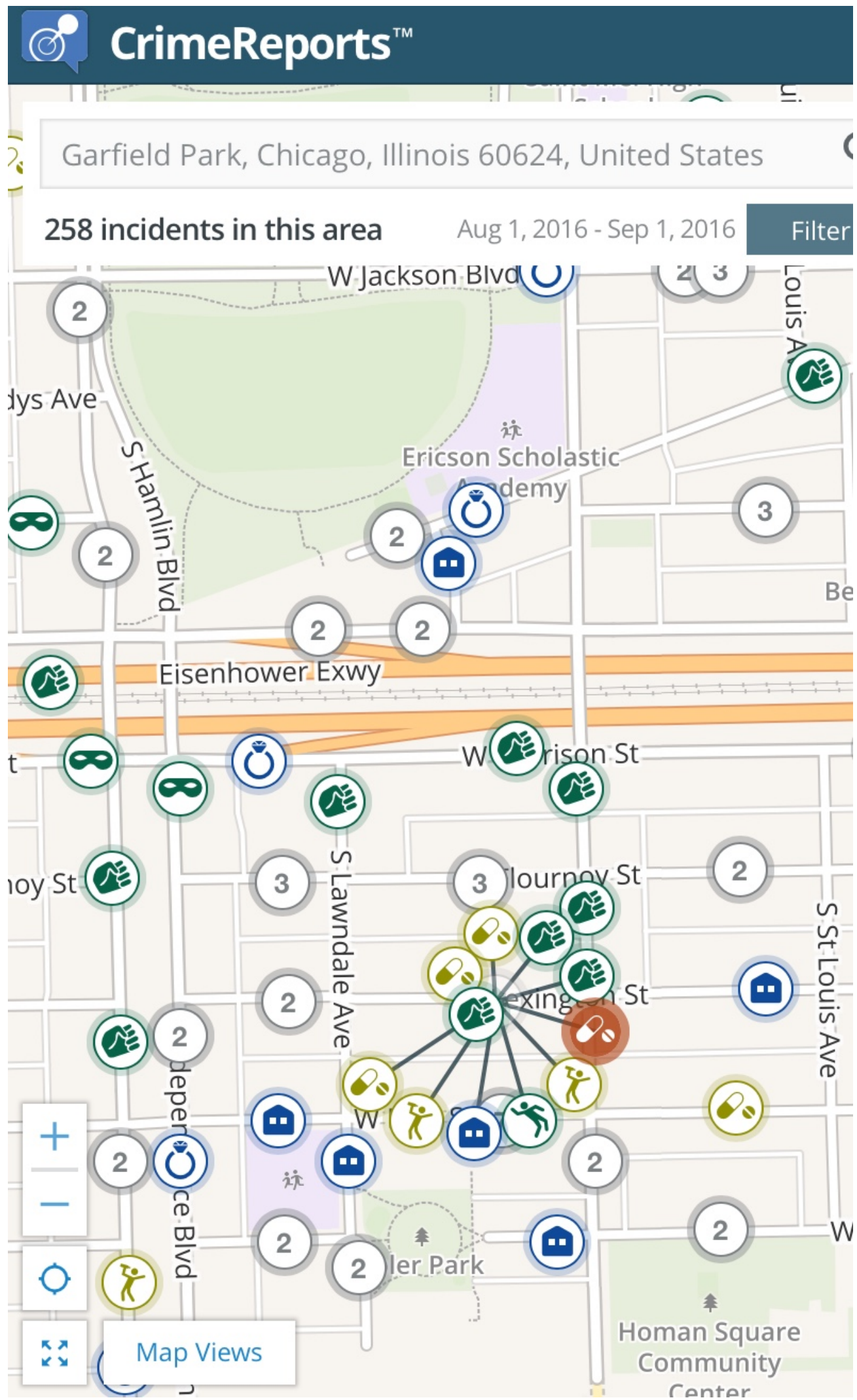

Figure 12. West Garfield, near Eisenhower Expressway. Yellow icons represent quality of life crime; circles with numbers represent clusters of crime on a block or address. Here, one of the clusters has been expanded to demonstrate the types of crime within. There are several types of quality of life crime, as well as violent crime 
(green) and property crime (blue) that are often associated with the sale of drugs and alcohol (Paynich and Hill 2010). Pill icons in yellow represent drug crime (sale, possession, or manufacture). The human figure holding a bottle (yellow) represents disorderly conduct, whether or not the individual is under the influence. Out of the eleven clusters of a total of 24 crimes, fourteen of those crimes were quality of life crimes. Of those fourteen, ten were drug possession or sale crimes, and four were disorderly behavior/conduct.

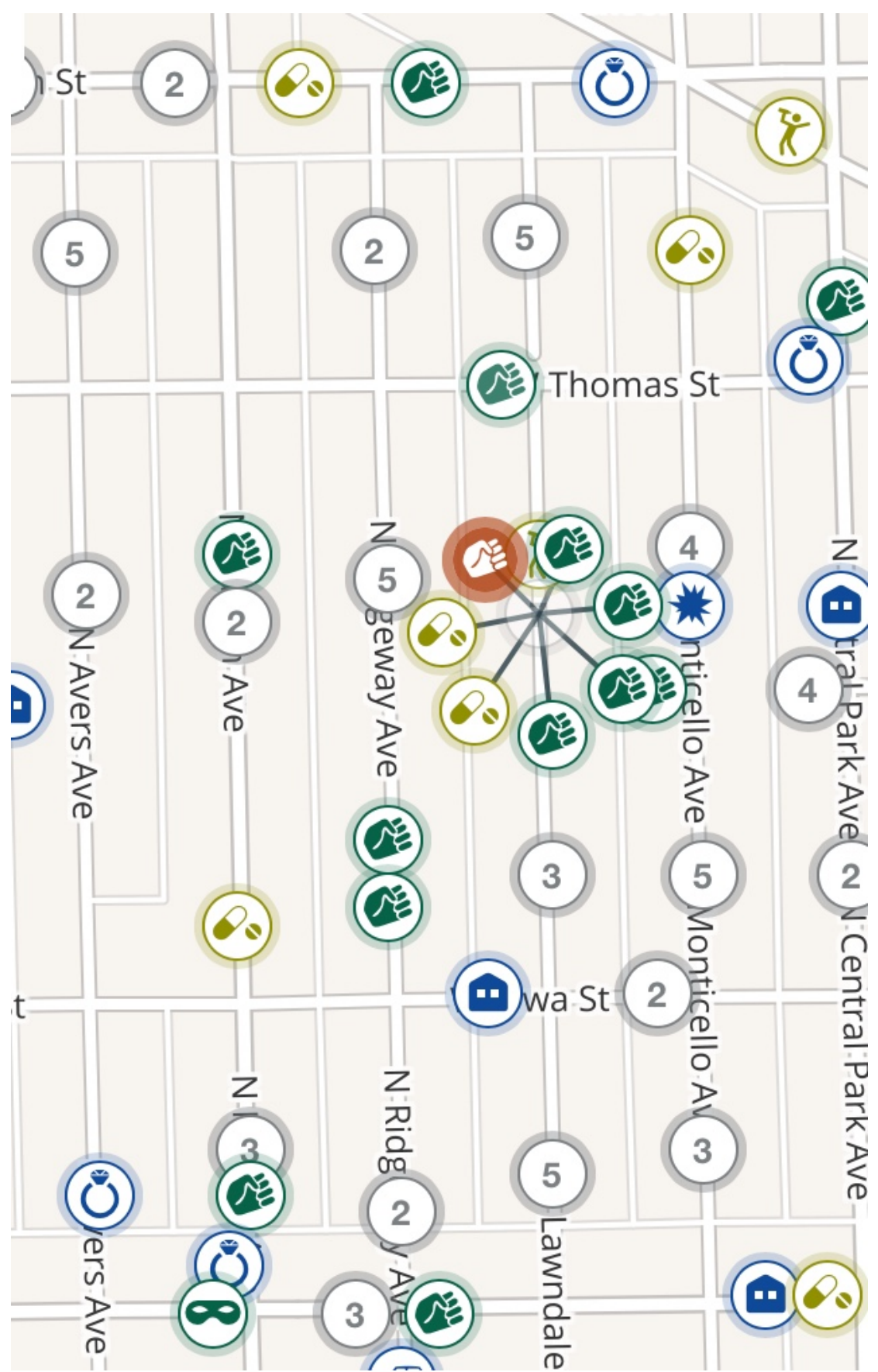

Figure 13. Humboldt Park, near Humboldt Park and Grand Avenue. Yellow icons represent quality of life crime; circles with numbers represent clusters of crime on a block or address. Here, one of the clusters has been expanded to demonstrate the types of crime within. There are several types of quality of life crime, as well as violent crime (green) and property crime (blue) that are often associated with the sale of drugs and alcohol (Paynich and Hill 2010). Pill icons in yellow represent drug crime (sale, possession, or manufacture). The human figure holding a bottle (yellow) represents disorderly conduct, whether or not the individual is under the influence. Out of the twenty- 
six clusters of a total of 59 crimes, 38 of those crimes were quality of life crimes. Of those 38, 28 were drug possession or sale crimes, nine were for disorderly behavior/conduct, and one was for a minor in possession of alcohol. The elevated drug crimes are suggestive of correlating criminal behavior, which could explain the high clusters of crime in this area.

\section{Drug Crime within Quality of Life Hot Spots}

In Humboldt Park, a further filtering of quality of life crime into only drug crime revealed an area that either had significantly more drug activity than every other examined neighborhood, or police presence was significantly higher (fig. 14). Although difficult to identify the circumstances around each drug arrest from Tribune reports (which were few), and Crime Reports, the key findings were: proximity to one another; type of drug; location (street, car, non-commercial building, commercial building, school, etc.). The findings and data showed an elevated presence of white heroin, followed by crack and cannabis. Cannabis arrests tended to have other crimes in the same location that had the same date and location, leading to the assumption that police may have arrested an individual for a larger crime, such as assault, and finding a secondary charge of cannabis possession. 


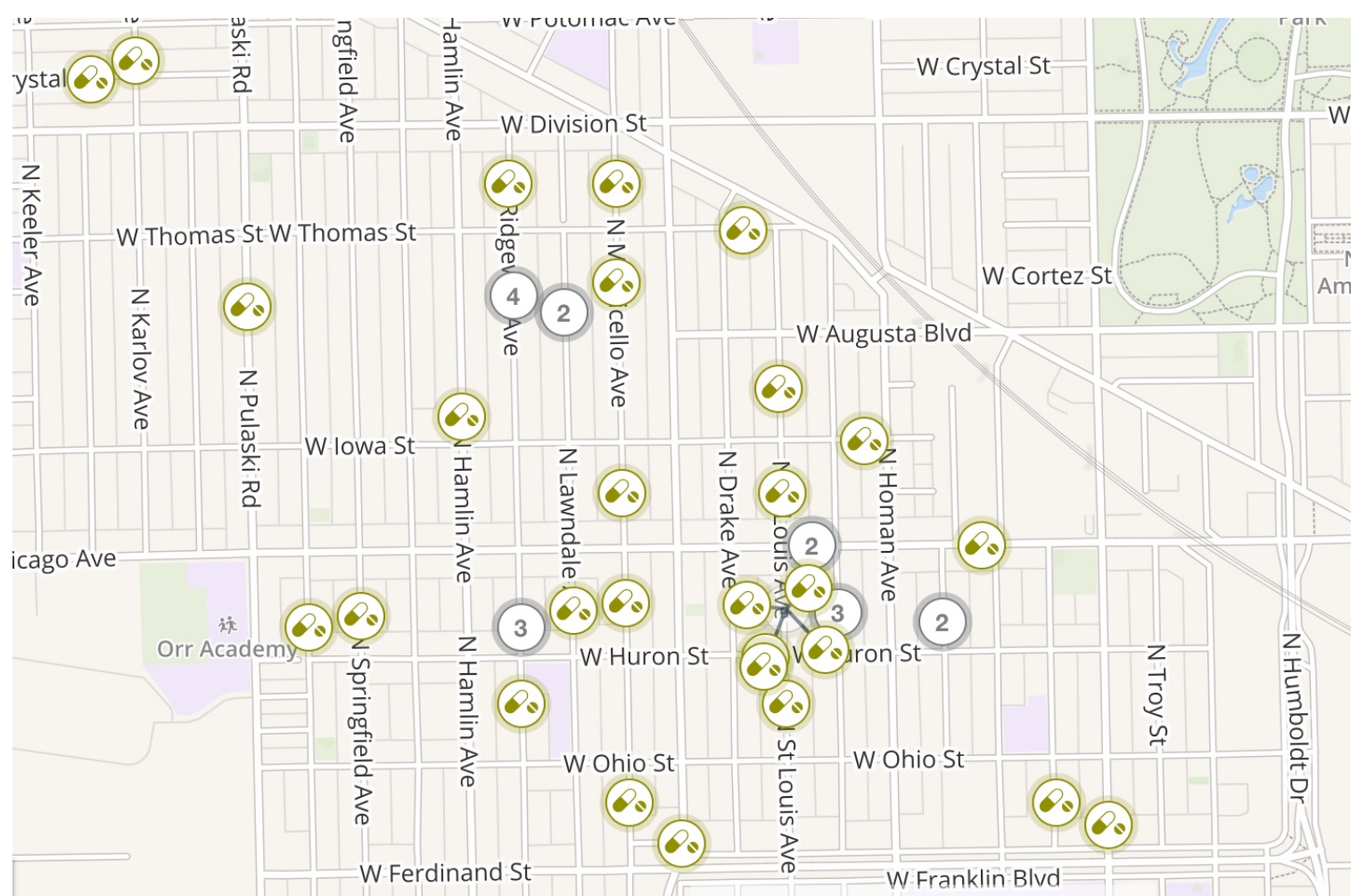

Figure 14. Humboldt Park Drug Crimes. In this section of a map from Crime Reports, only drug crimes have been shown. Quality of life crimes are depicted in yellow, and the pill icon refers to drug arrests for possession, sale, or manufacture. This map contains 44 police reports on drug crime from Aug. 1, 2017 - Sept. 1, 2017. Of the 44 reports, 12 were for cannabis possession, 28 were for white heroin, one for PCP, and three for prescription opioids. Also of the 44 reports, 12 were made after arresting an individual for the sale of narcotics. Of these 12, two were for the sale of marijuana (under one pound), and the rest were for the sale of white heroin. Chicago Police noted in several Tribune articles the difficulty in catching low-level drug dealers, as they usually keep their larger supply hidden, while carrying a minimal amount to sell-thereby minimizing chances of being caught or receiving a stiffer penalty or jail time.

\section{Prostitution}

By changing crime filters on Crime Reports, certain types of crime can be examined without visual interference from other types of crime. During an examination of each neighborhood, each type of crime was isolated and each individual community was tested for hot spots. During this process, the community of West Englewood revealed a cluster of prostitution crimes (fig. 15). No evidence could be found of a reported prostitution sting in West Englewood. Whether a sting was performed or not, there is evidence of a corridor of prostitution in West Englewood. Although prostitution 
arrests were evident in every studied region, West Englewood presented the only hot spot evidence.

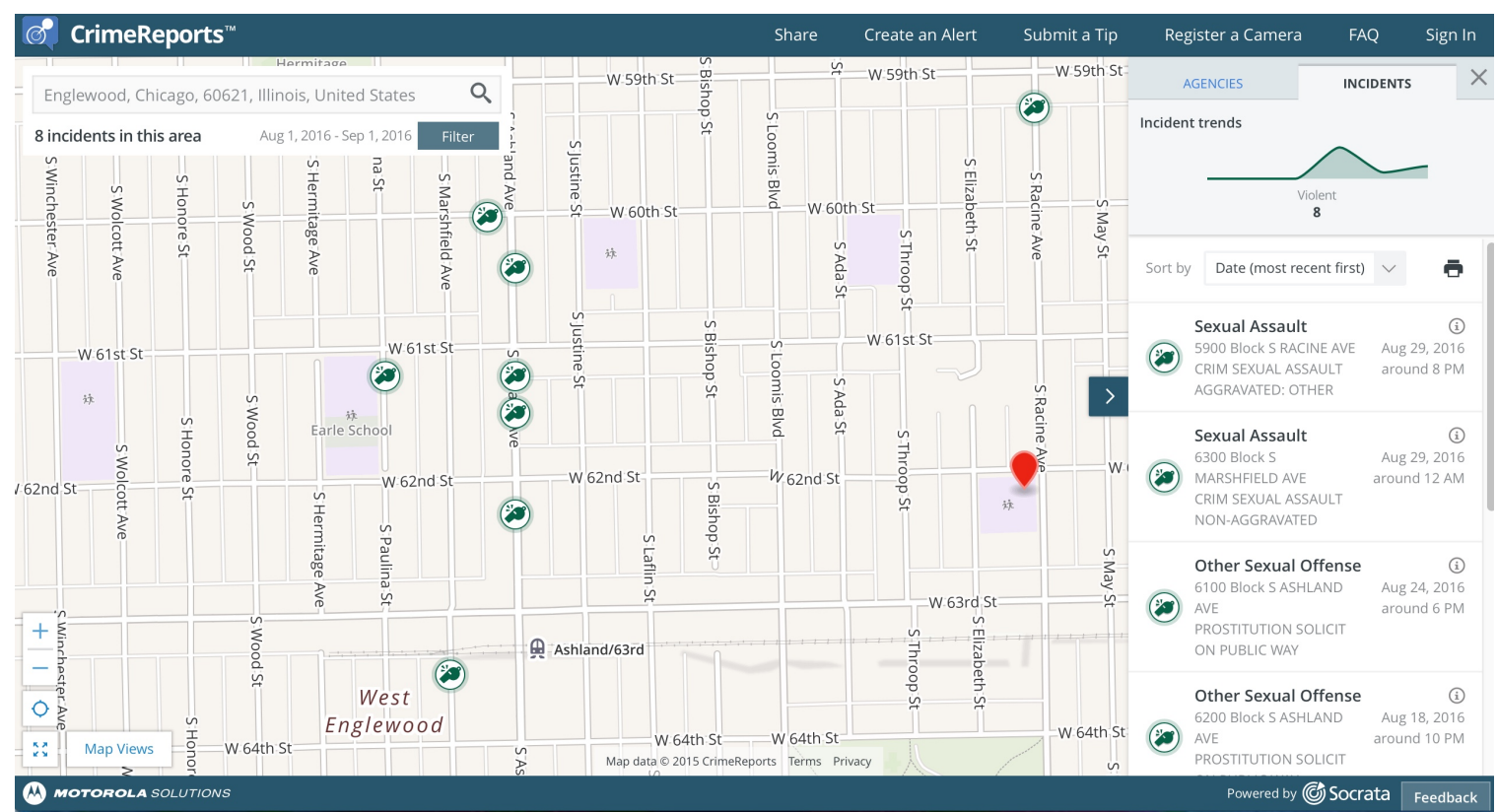

Figure 15. West Englewood prostitution and sex assault cluster. This map detail has been filtered to only show sex crimes. In this case, the green icons that show a whistle represent violent crime of a sexual nature. To the upper right on Racine Avenue, lower left on S. Marshfield Avenue, and near a school on $61^{\text {st }}$ street to the west, are three reported sexual assaults (two aggravated, one non-). However, there are five reported cases of prostitution (solicitation on a public way) from different dates, suggesting that there was not a singular police sting, but several cases of prostitution that occurred in one month.

\section{Arson}

Arson is a relatively rare crime, but one that was reported much more regularly through news media and the Tribune. What wasn't reported, however, and not part of the research on the regions of West Side, South Side, and Wrigleyville, was an area just to the west of West Garfield Park called The Island. It showed a very clear hot spot of arson that was isolated from other arsons and communities (fig. 16). 


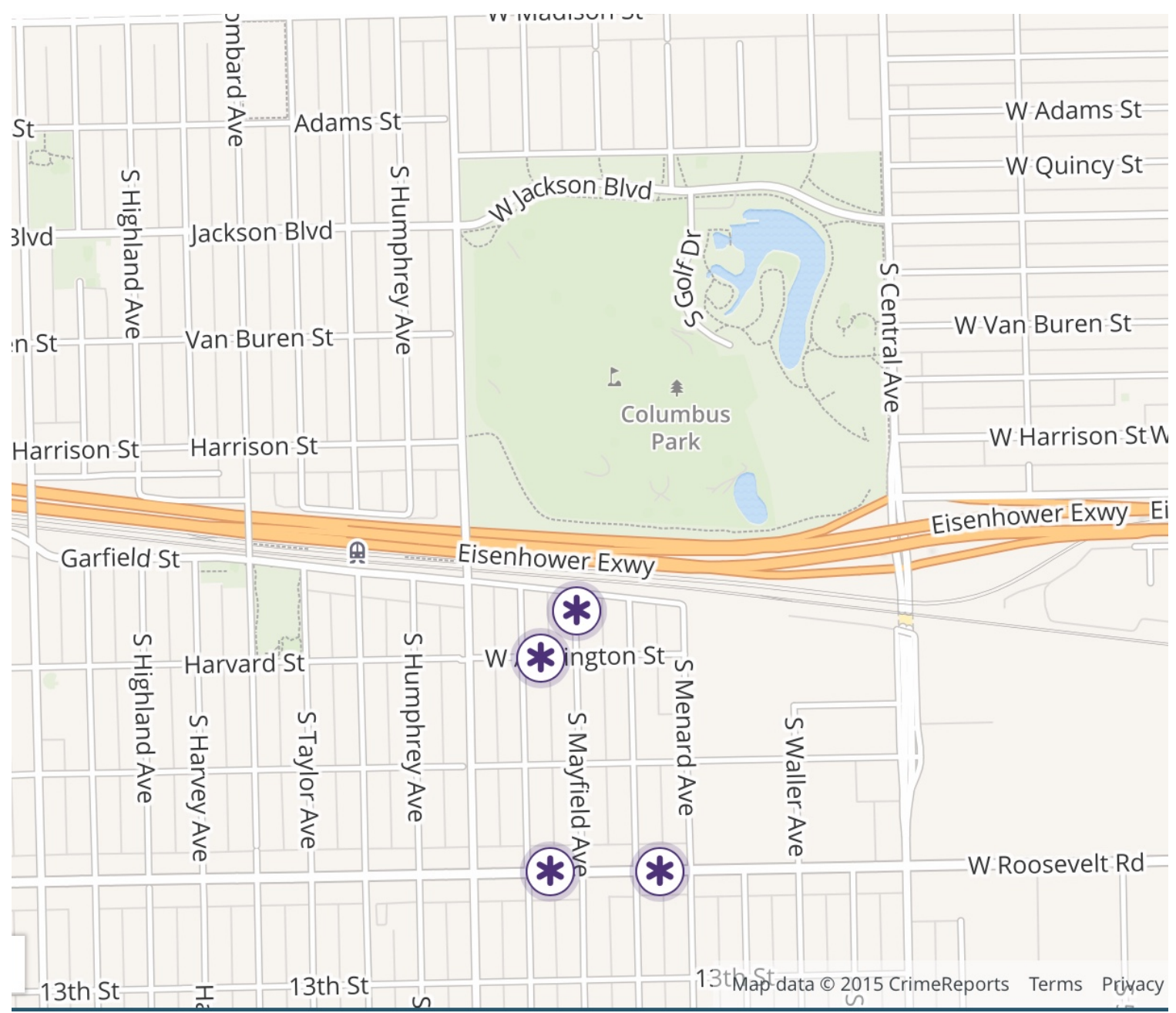

Figure 16. Arson cluster in The Island. There were a total of eight reported arsons (either during the month of Aug 1. 2017 - Sept. 1, 2017 or retroactively due to investigation length) in the city of Chicago. Of those eight, four appeared in a tight cluster in an area called "The Island" just south of Columbus Park. According to the Tribune, there were no arrests, and Crime Reports has not listed any arrests made in conjunction with the arsons. Because there was no reporting by the Tribune, it might be assumed there was no loss of life, as the Tribune attempts to report every crime that involves a loss of life, as noted by their shooting and homicide map and coverage over other arsons that have ended in a loss of life.

\section{Sex Offenders}

Research showed that registered sex offenders lived in all studied communities.

There were clusters in each region that were eliminated after further review showed these were clusters based around Crime Reports coding. If there were 16 sex offenders without a valid address within a zip code, Crime Reports automatically placed 16 sex offenders in the geographic center of the zip code. This research did not include these sex offenders in 
the finding or discussion, since the data was unreliable. Also unreliable were smaller clusters, since community housing was unverifiable. Since these sex offenders had valid addresses they were included in the findings and discussion.

Humboldt Park had the most sex offenders and concentration of sex offenders of the studied communities (fig. 17). This was, in theory, due to being encircled by a ring of schools (fig. 18).

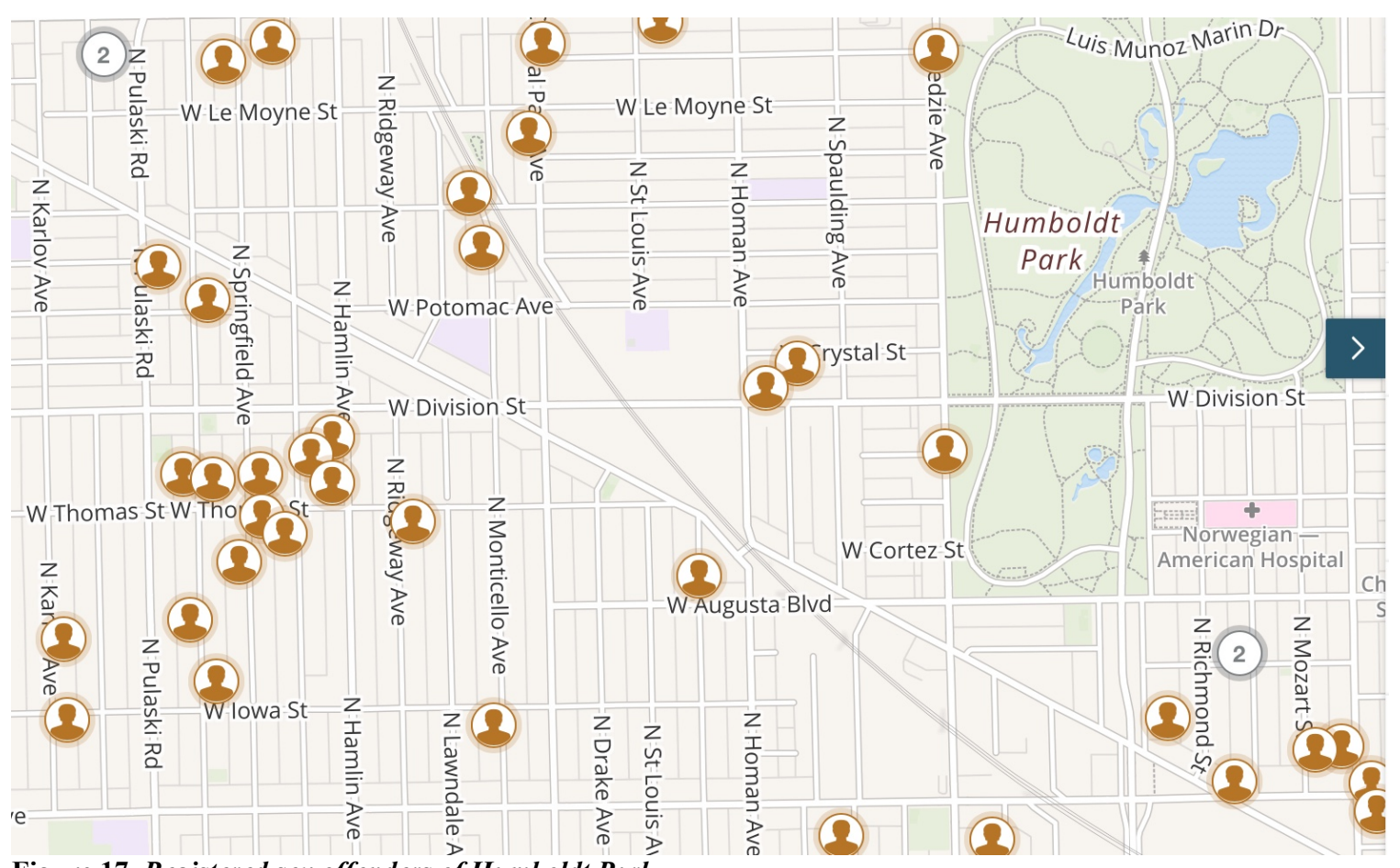

Figure 17. Registered sex offenders of Humboldt Park 


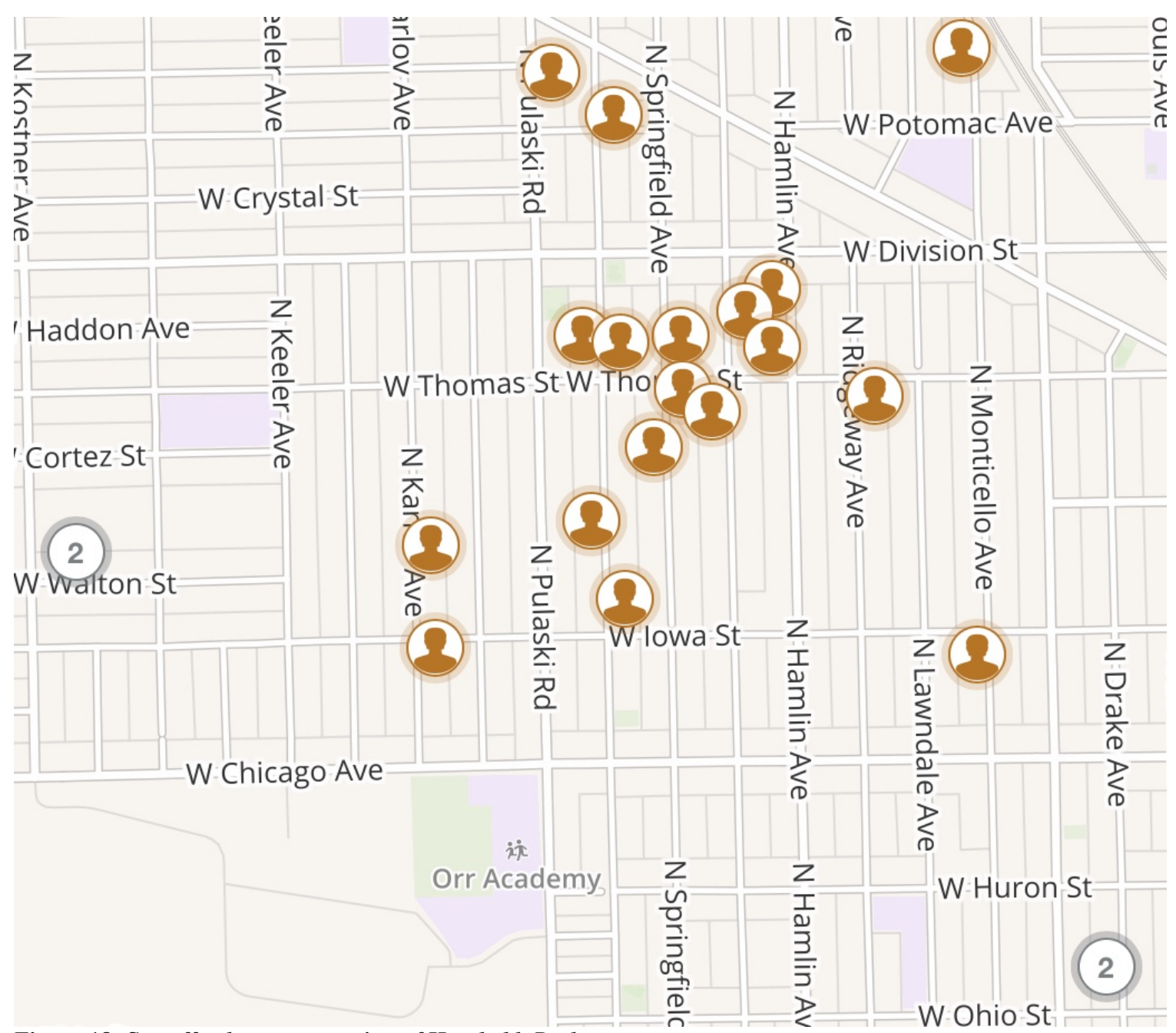

Figure 18. Sex offender concentration of Humboldt Park

\section{Alcohol and alcohol-selling establishments}

Crime Reports does not display many liquor stores or bars on its maps, and any quality of life data concerning crime directly related to other crime is difficult to establish; many crimes are committed under the influence of drugs and alcohol. Paynich and Hill (2010) discovered that $42 \%$ of all nonfatal intimate partner abuse occurred under the influence of alcohol or drugs, for example. Crime Reports does consider crimes under the umbrella of "alcohol," but the reported crimes are very few. They include "illegal consumption by a minor" at Lane Technical High School and "liquor license violation" at 
the Hideout Tavern. However, many crimes are committed in, or in close proximity to, liquor establishments. This is highly evident in the case of Wrigley Field.

The area directly surrounding Wrigley Field has numerous bars, taverns and establishments that sell alcohol. Most of them line N. Clark Street and Sheffield Avenue to the immediate south of Wrigley Field. The combinatory tally of crime is much higher in this location than anywhere else in the three communities that comprised the Wrigleyville area covered by this research: Lake View, Lincoln Park, and Uptown. The most notable were assaults and robberies that occurred in the Clark and Sheffield area (fig. 19), totaling 86 reported crimes, according to Crime Reports. More numerous were the amount of thefts that took place in the one-month window. During the month of August 2016, there were sixteen home games between the Chicago Cubs and other Major League Baseball teams. There were also twelve away games during this period, and four days of no baseball. The local bars feature events and coverage of the away games, leading to a culture of drinking and watching Cubs games. Of the 86 reported crimes, 80 occurred during baseball games. By comparison, an examination of crimes logged by Crime Reports from Feb. 1 - Mar. 4, 2017, yields only 13 crimes in the same area of Clark and Sheffield (fig. 20).

The resulting data demonstrate that Wrigley Field, and the drinking establishments that fuel fans, directly affect crime rates in a significant way that has been largely ignored by Tribune reporting. 


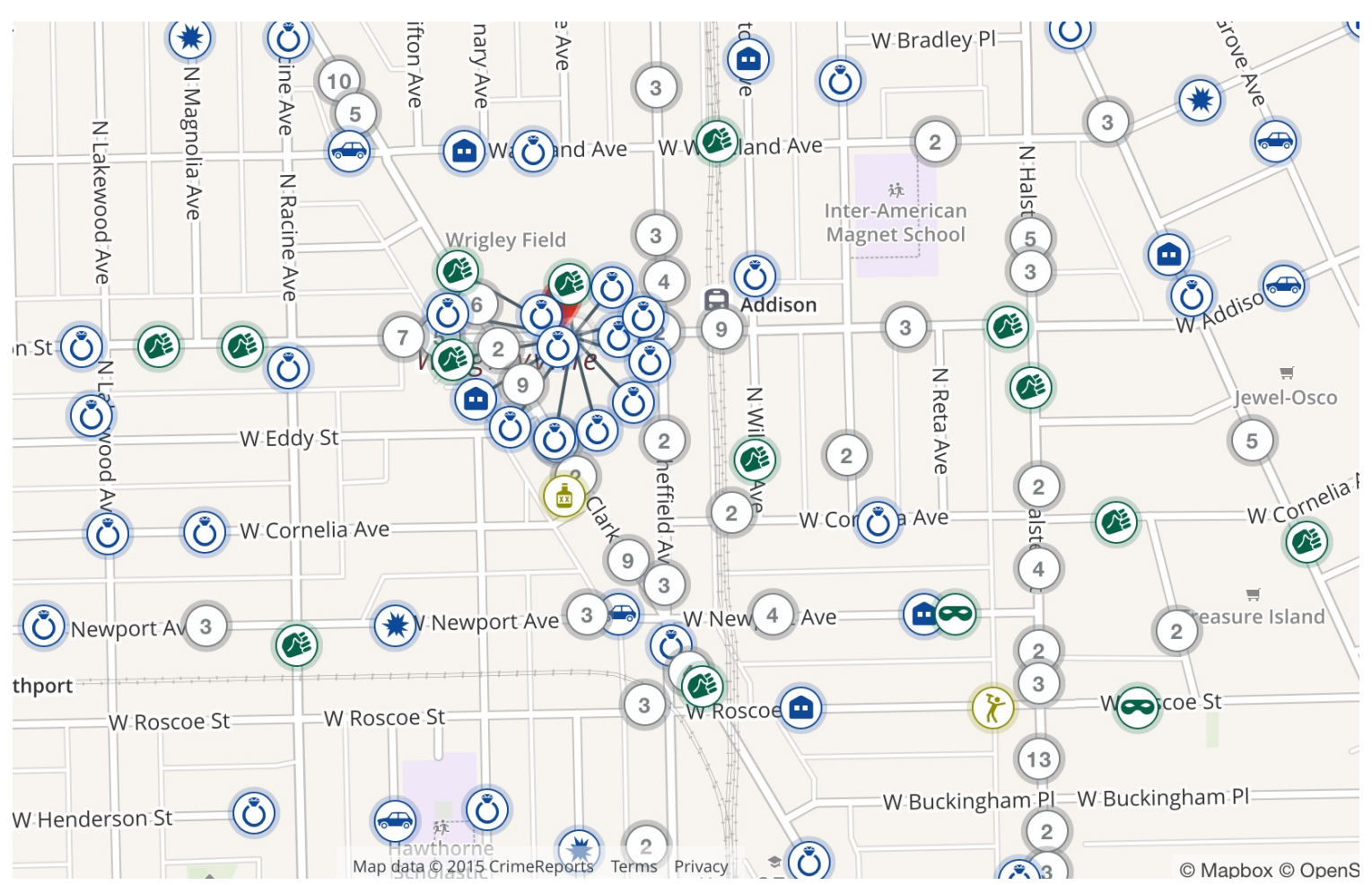

Figure 19. Total crime surrounding Wrigley Field. The cluster of crime surrounding Wrigley Field and its alcohol establishments far exceeds the surrounding area. During Aug. 1 -Sept. 1, 2016, there were sixteen home games at Wrigley Field between the Chicago Cubs (who were first place in their division at the time) and other Major League Baseball teams. In the month of August 2016 there were 86 reported crimes in the immediate block surrounding Wrigley Field and down the strip of bars on $N$. Clark Street, according to Crime Reports, and 66 of them occurred during home games. Fourteen more occurred during the 12 "away" games, which are broadcast and featured at local bars in the area. Only eight crimes occurred during the four days that did not feature a Cubs game.

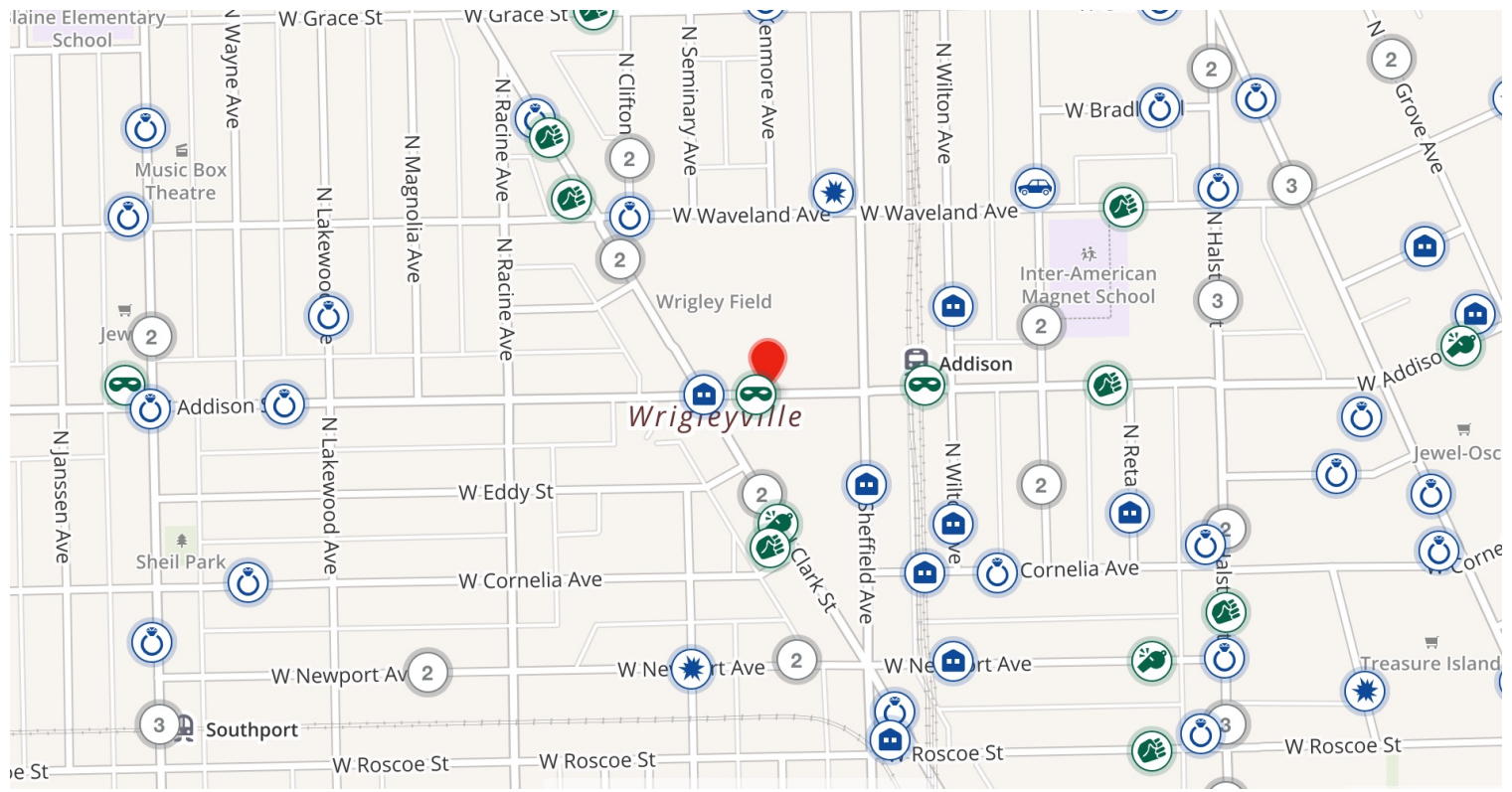

Figure 20. Wrigley Field during baseball off-season: Feb. 1 -.March 4, 2017. Pictured is the same geographic area in Figure 19. Compared to August 2016's 86 reported crimes, there are only 13 reported crimes, according to Crime Reports. 


\section{Watercraft}

During the examinations of crime in communities, one area stood out as having the most theft within a confined area, with about $4 \mathrm{x}$ the amount of thefts than the secondmost significant area (West Garfield). This was just outside of Lake View in Belmont Harbor, and it appears these thefts took place on the moored and docked watercraft in the harbor, in addition to adjacent parking garages for local museums and parks in the area. There were 22 thefts from watercraft and buildings in the harbor reported in the month of August 2016 (fig. 21). A Crime Reports review of other harbors and moors along the Lake Michigan coast in Chicago show no other hot spots of activity related to watercraft. Beach areas tended to attract theft from persons and automobiles, but harbors showed no other significant activity. Why Burnham Harbor is an anomaly is unclear and in need of further investigation and reporting.

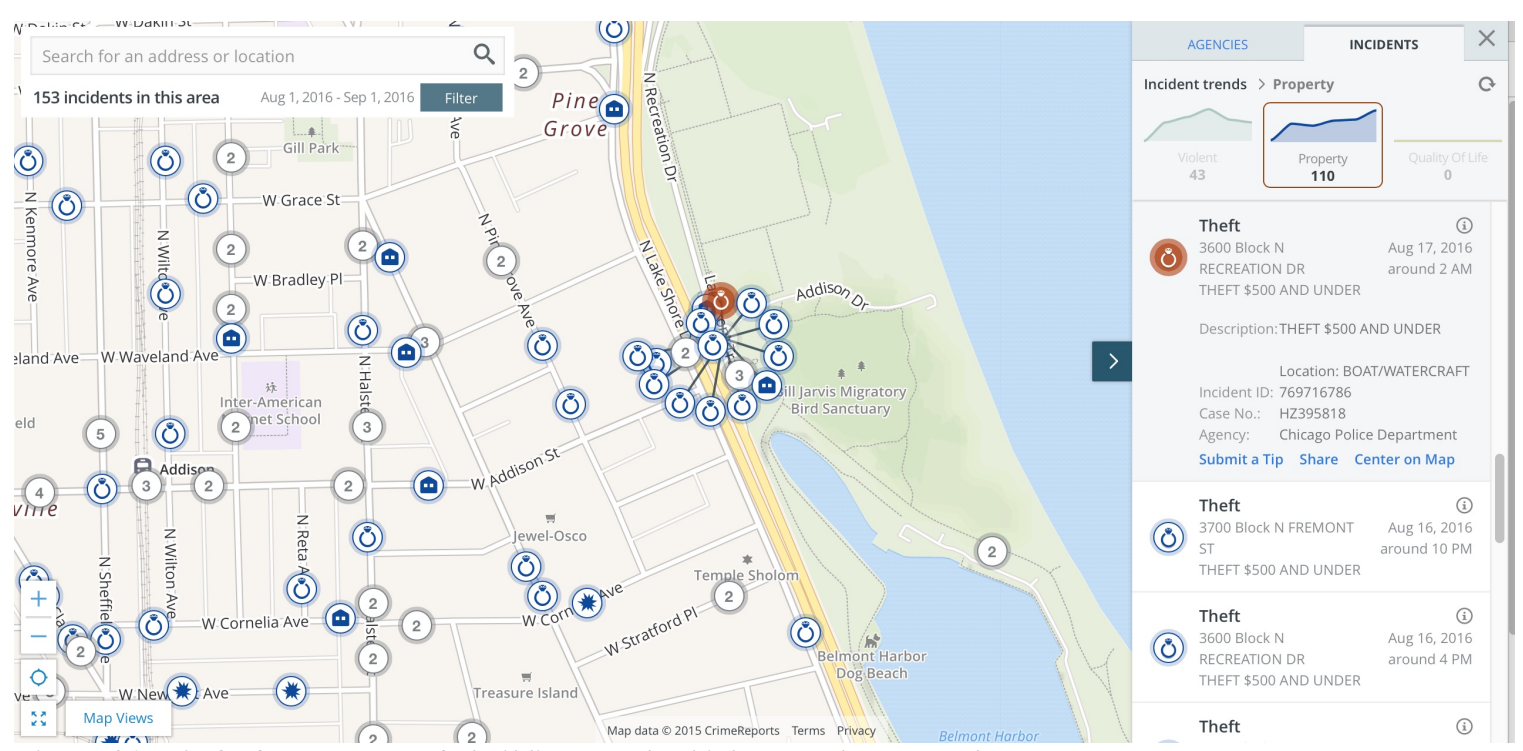

Figure 21. Thefts from watercraft, buildings, and vehicles at Belmont Harbor 


\section{Chicago Tribune}

From Aug. 1 - Sept. 1, 2016, all crime reports from the Tribune were recorded and logged, then plotted onto Google Maps. This included print and digital versions. Print stories were separated and scanned by two methods to ensure that they were correct: by the print PDF supplied online, and by the ProQuest database, accessed through Northern Illinois University's library system. Each crime was logged according to the following legend:

Orange Pin: Shooting \& Gun Violence Crime

Brown Pin: Vehicular Hijacking, or "Carjacking"

Yellow Pin: Hate Crime

Black Pin: Felony Gun Possession

Green Pin: Burglary/Robbery

Red Pin: Homicide

Pink Pin (1): Sex Crime

Blue Pin (2): Arson

Black Diamond: Alcohol Establishment

Yellow Star: Youth Facilities and Schools

Victims' names reported by the Tribune were logged. The Tribune provided gender and age for most violent events, such as shootings and homicides. The more grievous the crime, the more often the name was reported. This includes gun violence against children, homicides, and violence against celebrities or family of celebrities. In all cases possible, a quote from the news article was posted to the "pin" on the map that summed up the majority of information related to the crime. In many events the Tribune 
merely provided a series of mug shots, shooting maps, blotters, etc., that provided little information.

Almost all reported crimes had a location that could be plotted. All crimes that did not have a location or block were not plotted on the map. These were few and potentially insignificant. Nearly all of the "location-less" crimes consisted of shooting victims that did not say where they were shot, but self-reported to a local hospital, such as Stroger Hospital, after someone other than an ambulance transport them. One outlier of "locationless" data plots consisted of sex offenders that had no current address. Crime Reports, whether by design or by way of algorithm, plotted their locations at the center of their last known zip code. This anomaly was easy to identify, as there would be a cluster of between 11 and 24 sex offenders, which was cross-referenced with a United States Postal Service zip code map to determine an approximate geographic center.

\section{West Side Chicago (Humboldt Park, East Garfield, West Garfield)}

The Tribune reported very few crimes for this area of West Side Chicago during this time period: eight crimes, compared to 1,720 reported crimes from Crime Reports. Less than half a percent of crimes were reported in the Tribune $(0.47 \%)$. Of these crimes, one was a homicide, and seven were from gun violence.

\section{South Side Chicago (New City, West Englewood, East Englewood)}

The Tribune reported thirteen crimes in these communities, compared to 2,032 reported crimes from Crime Reports. Less than $1 \%$ of crimes were reported in the 
Tribune $(0.733 \%)$. Of these crimes, three were homicides, one was arson, and nine were from gun violence.

\section{Wrigleyville (Uptown, Lake View, Lincoln Park)}

The Tribune reported only one crime, compared to 1,826 reported crimes from Crime Reports. This amounts to $5 / 100^{\text {th }}$ of a percent $(0.055 \%)$, a substantial void of coverage. Of note, Tribune Tower, the epicenter of the Chicago Tribune's staff and reporters, is located a few minutes south of Lincoln Park.

\section{Sample of Print Tribune Stories}

A comprehensive examination was conducted on each daily edition of the Tribune from Aug. 1, 2016 - Sept. 1, 2016. Every story that had an element of crime reporting was logged as a short summary in order to provide a reference for data collecting. The following is a one-week sample:

Aug. 31:

- Warning to people living in North Shore neighborhoods about elevated car hijackings and car theft.

Aug. 30:

- Citywide story about the massive shooting and homicide rate for Chicago, as August wraps up to be the deadliest since 1997. Tavon, a child who was shot in front of his twin sister, is used as an example. He is later featured in a long form piece.

- Nykea Aldridge, 32, cousin to Dwayne Wade, NBA Chicago Bulls star, was shot when two men attempted to fire on a driver. She was a mother of four, and she was pushing an infant in a stroller.

Aug. 29:

- Brothers charged in the death of Nykea Aldridge, 32, cousin to Bulls star Dwayne Wade.

- Story about a mother renting out billboards to find person(s) that burned her son alive in Gary, Ind. 
- Shooting and homicide blotter: two murders, three logged shootings, and five injuries from a shot man driving himself to the hospital, with only ages and hospital locations (no locations or further information).

- "How Donald Trump would eliminate crime in Chicago."

Aug. 28:

- Using FOIA, the Tribune looked at police shootings over the past six years. Of note: A little more than half of the officers who fired shots at people were minorities -- 84 Hispanic officers (28 percent) and 69 black officers (23 percent). White officers made up 45 percent of the total -- 136 officers in all. The other officers were listed as Asian/Pacific Islander. The officers also tended to be experienced, not rookies who suddenly found themselves in over their heads. The records show officers who have shot at citizens had an average of about nine years on the job. In the past, the Independent Police Review Authority has not tracked officers involved in multiple shootings if the shootings were deemed justified.

- Rhymefest [Che Smith] "disgusted" by police treatment after armed robbery.

- "Officers get pranked, taunted on scene."

- "Dwayne Wade's cousin fatally shot."

- $\quad$ Building fire kills several people; cause of fire under investigation.

Aug. 27:

- "Dwayne Wade's cousin slain while walking baby in stroller."

Aug. 26:

- "Teen's shooting death a loss for all: Arshell Dennis III, son of a Chicago cop, was a reason to see hope in city's future."

- "Violence, race on agenda: Local athletes, others meet to discuss 'desperate ... crisis.",

- "Convicted woman is granted bond: Mother who killed disabled daughter appealing sentence."

- "Fatal arson: Man 'tried to go get the girls': 4 deaths from fire on South Side all ruled homicides."

- "Heroin supplier heading to prison: Man pleads guilty, gets 6-year term in death of woman."

- "Trial starts for Prairie Grove cop accused of DUI: Officer allegedly crashed police SUV while drunk."

Aug. 25:

- "2 deaths ruled homicides in fire; 3 sisters, man lost: Infant died of injuries when dad jumped with her."

Aug. 24:

- "Cop: Men drank on night of slaying."

- "'Just speechless': 3 girls and man killed in fire: Arson suspected at apartment building."”

- "New state law toughens gun trafficking penalties: Governor signs measure without legislative dueling." 


\section{Logging Digital Tribune Crime Reporting}

In 2016, the Chicago Tribune developed data-driven, information-rich maps that addressed homicides. These are accessible to the public, but only online. In addition, reporters also developed a map of shootings. Each map provided a cartographic point where the victim was injured or killed. In the case of homicides, names were provided. In the case of shootings, only gender and age were provided. This information was crossreferenced with digital crime stories to corroborate location, age and gender to provide an accurate Google Map.

Unlike the print edition of the Tribune, more crime reporting was found online. The Tribune offered features such as "Mugshots in the News," which attached a mugshot with a criminal story summary that often yielded the block where a crime occurred, enabling a data point to be made on Google Maps. No matter the location, these points were plotted within the city limits of Chicago.

\section{Summary}

Crime reporting by the Tribune represents less than $1 \%$ of all reported crimes as per the Crime Reports database. What effect does this have on a community? What choices must the Tribune editorial board make when pursuing crime stories that are as diverse and varied as the city?

\section{Google Maps}

Overwhelmingly, the Tribune reported shootings and homicides, as noted by their data-driven, interactive maps and police blotter reports. A total of 81 shootings and 21 
homicides were logged on Google Maps during the month of August 2016. By comparison there were seven vehicular hijackings (carjackings), one hate crime, two felony gun possessions, three robberies/burglaries, one sex crime, and two arsons. As seen in collected data from Crime Reports, this is a disproportionate number that demonstrates the sensational nature of violent crimes versus nonviolent crime. By nature of sensationalism, crimes that are different, shocking, or more violent than what people are used to provoke intrigue.

Nonviolent or typically nonviolent crimes were reported only when they had an angle of interest. One example is that of embezzlement from a Russian orthodox church, reported by the Tribune. Theft is a common crime, but rarely reported. Crime Reports distinguishes between thefts less than $\$ 500$ and those greater than $\$ 500$. In almost every case, all thefts went unreported by the Tribune. One arson crime, out of eight, was reported in all of the researched communities, and the story detailed how several children were murdered because of the arsonist. This is relevant because arson is not a common crime, but unless the loss of life in involved, or unless a significant structure of historical or cultural value is lost, the story most likely will go unreported.

There is disconnect between the type of crimes that are reported by the Tribune and those reported by Crime Reports. The result is a massive amount of stories that are not reported or investigated by Tribune reporters. The year of 2016 saw the most gun violence in two decades (Gorner, 2016). The Tribune covered the violent, recordbreaking year by increasing reporting, statistics, and data-driven maps of shootings and homicides, compared to the three preceding years. Very few nonviolent crimes were published in August of 2016. Some samples of nonviolent news from the Tribune 
include: a sexual assault on a female water polo athlete during a co-ed high school match; a report on the large number of drowning victims in Lake Michigan; a FOIA report on police-related shootings; a heroin dealer is sent to prison after a woman dies from drug use; an article on gun trafficking; a Prairie Grove police officer faces trial after driving drunk, etc. 


\section{DISCUSSION}

\section{The "Bewildered Herd"}

Reporter and writer Walter Lippman wrote, in 1922, of the pseudo-environmenta fabricated perception of our every day interpretation of the world around us. As humans, we are able to concentrate fully on one subject at a time. When we are writing, for example, someone interrupts our thought process when she or he talks to us. We cannot physically or mentally write and carry on a meaningful conversation. The same situation can be seen when we consume media - we can observe one form of media at a time with any meaningful result. Because of this we live in Lippmann's construct of a pseudo-environment. We are limited to a small amount of information, and, ultimately, we shift erratically with news events. We chase sensationalism as a "bewildered herd," and we offer our opinions on day-to-day matters in a somewhat incoherent manner (n.p.).

The website Crime Reports and the establishment news publication Chicago Tribune, are, by nature, vastly different vehicles for information to the "bewildered herd." While they have been used to compare and contrast crime data for the purposes of this research, their purposes differ. Crime Reports functions as a repository of police agency reports - in this case the Chicago Police Department - and allows users to interactively filter dates, crimes, and geo-locations. The Tribune serves the public, and relies upon the public, to function as a watchdog and chronicler of politics, culture, sports, crime, fashion, and a number of topics that affect everyday life. Although these two entities are different, they do augment one another. As shown in many examples in this research, 
there exists potential to function in data symbiosis. Subscribers may appreciate knowing the story behind the crime, but what happens when most of the crimes are not reported, or are unable to be reported due to volume, time, or location? Additionally, reporters can rely on the metadata provided by Crime Reports instead of attempting to discover large amounts of details from the police. This type of journalism isn't restricted to professional journalists from the Tribune or other publications; there exists an area that can be filled with citizen journalists that can augment the reporting of less sensational crimes.

Reporters Bosman and Einhorn (2016) visited Chicago over Memorial Day weekend in 2016, hoping to use social media to their advantage as they, for the New York Times, covered what they presumed would be a violent weekend. Historically, Memorial Day weekend has been particularly violent for Chicago; 2016 turned out to be just as horrific, and the Times had put reporters and analysts in place for the violence they predicted would occur. Bosman and Einhorn monitored Twitter, police scanners and Facebook to seek out reports of shootings and violence, and they updated their office in real-time, hoping to discover hot spots in violent crime. What they discovered over a three-day weekend was enough to provide the Times with several stories as the reporters tracked down victims and shared their lives before and after being shot. Such an undertaking from a large, respected newspaper took many people, working together, to report one weekend of crime. Their example demonstrates the difficulty in covering stories of violence in Chicago, much less nonviolent crime. It is important to have citizen journalists, and to use data, in a broader effort to report, prevent, and reduce crime.

By addressing the findings from the analyses of Crime Reports and reported crimes from the Chicago Tribune, we can understand better the reasons to undertake the 
analyses and learn from the results. In a section-by-section breakdown, this research intends to foster a dialogue among fellow researchers, improve credibility among journalists at the Tribune, and empower citizens. Reporters cannot do this job alone and expect to provide enough coverage for the city to grasp the scope and magnitude of crime.

\section{Schools}

The Tribune extensively covered the closure of schools under Mayor Rahm Emmanuel (fig. 22), which included an interactive, researched, Google-based map (fig. 23) that provided a lot of informative data for the public. However, the Tribune did not cover crimes associated with school closure or the prevention of crime related to the presence of a school. While crimes from and against children are sensationalized and often reported, there are other factors worth noting and reporting, such as the presence of a school as a buffer to deter crime.

While crime surrounding schools is complicated and researchers can be conflicted as to the benefits of a school, a Glitch Theory analysis of Crime Reports maps clearly shows the schools tend to act, from a basic visual analysis, as a deterrent or "buffer" to crime. Paynich and Hill suggest that urban schools sometimes act as a catalyst to robbery and burglary in the immediate, surrounding area (2010), but these are often junior high or high schools. Elementary school student populations are much less capable of committing serious crime. Parents, police presence, and young students exercising self-control often serve as deterrents to serious crime (Wikström, 2012). 


\section{SCHOOL BOARD VOTES TO CLOSE 49 SCHOOLS}

The following scoreboard reflects how the Chicago Board of Education dealt with the 54 school closing recommendations on its agenda.

Schools marked black are to be closed and schools marked blue are to remain open.

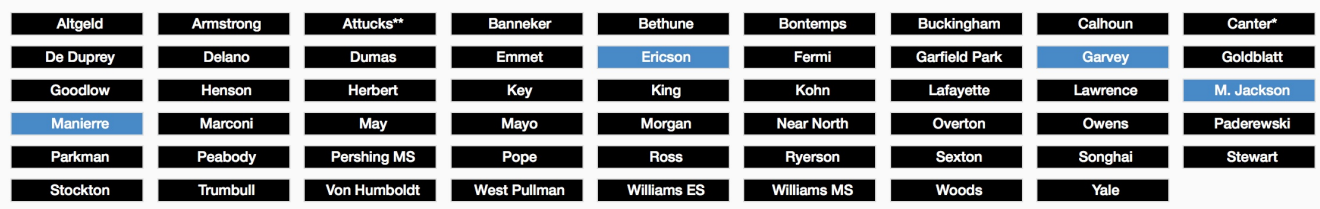

*1-year delay $\quad$ * 2-year delay

Note: Only 53 schools shown; the Board also voted to close the high school that shares space at Madison elementary and middle schools. CPS CEO Barbara Byrd-Bennett withdrew her recommendations to close Ericson, Garvey, Mahalia Jackson and Manierre schools prior to the meeting. At her request, the board voted not to close those schools.

After hearing from aldermen, angry parents and community members in a meeting interrupted several times by protesters, the Chicago Board of Education approved a plan to close 49 elementary schools and one high school program. Read more...ष
The map and list below contain more details about each of the schools being considered for closure, as well as those that will be welcoming students from other schools.

Figure 22. List of school closures from CPS (Chicago Tribune, 2013)

\section{Background \\ - Community areas by change in the population of school-age children Community areas by poverty rate Proposed 2013-14 elementary school attendance boundaries \\ The shaded areas on the map correspond to changes in the school- age population, children between the ages of 5 and 17, in each of Chicago's 77 community areas from 2000 to 2010 , based on an analysis of 2010 Census Data by the Tribune. \\ Increased school-age population, $0.1 \%-28.3 \%$ \\ Decreased school-age population, $0.1 \%-20.0 \%$ \\ Decreased school-age population, $20.1 \%-60.0 \%$}

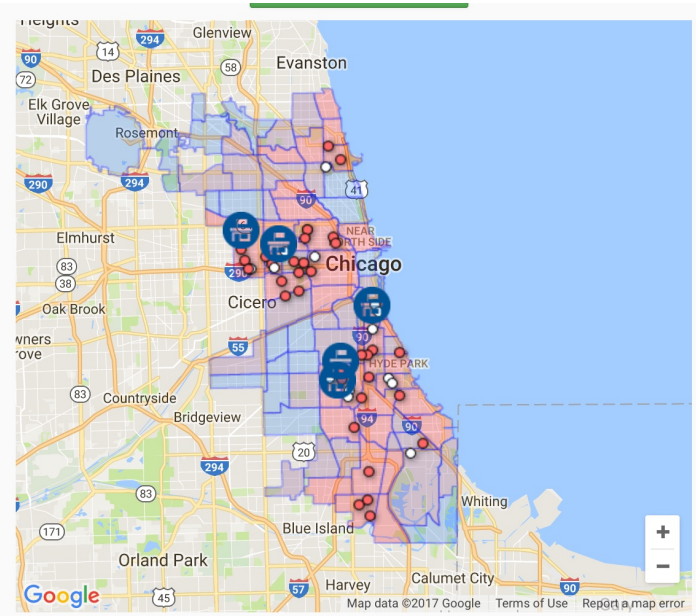

\section{Schools}

All affected schools

- Only closing schools

Only receiving schools

- School will be closed

Will receive students, but close and be relocated

\section{Extras}

More about these schools from the Tribune

Show my estimated location on the

map

Data used to generate this list include the Illinois Student Report Card from the Illinois State Board of Education and CPS Utilization Data, 2013.

Figure 23. CPS school closure report card (Chicago Tribune, 2013)

\section{Gang Territory}

Chicago has seen the decline of the large gang networks and the rise of "micro gangs"-smaller groupings of men and women that claim territory over smaller neighborhoods, blocks, or housing complexes. While they may still claim to be from a 
larger faction (i.e., Vice Lords, Black P Stones, Gangsta Disciples), micro gangs find leadership at a much smaller level. For example, the Mickey Cobras that claim the area from $43^{\text {rd }}$ to $51^{\text {st }}$ streets, and Shields Avenue to Wentworth Avenue, are broken down into four smaller groups, according to ChicagoGangs.org, Twitter and YouTube (2016): 43 ${ }^{\text {rd }}$ and Princeton; $45^{\text {th }}$ and Princeton; Dog Pound; and the Outlaws.

While the Tribune has written many pieces on gang culture, gun control, crime education of children, and the "end of drill rap" (Stewart, A., 2014), there is a notable absence in drill culture reports. Current scholarship suggests that drill culture is one of the main forces of gang culture and violence in Chicago (Stewart, F., 2016). Although few gang members travel far and are largely confined to a few community areas, they have an intimate knowledge of gang territory based on listening to drill rap music and watching drill rap videos, and by listening to what is playing on a particular street corner. They use drill rap to insult, taunt, and "call out" one another in provocations of violence (Stewart, F., 2016). It is very difficult to police drill rap music, but the Tribune could make a better attempt to educate the public on the cultural phenomena. Additionally, drill music, combined with social media, is largely seen as the main catalyst behind the advent of micro gangs.

Forrest D. Stewart (2016), an ethnographer and sociologist at the University of Chicago, explains that drill music is used to squeeze boundaries, threaten rivals, and place "hits" on people (acknowledge that they will be shot if seen). The Tribune could monitor drill rap videos and Twitter feeds, and report real-time reports to the public atlarge and the police, offering crime prevention rather than coverage. Mapping drill music is not all that different than the process involved in creating gang maps. The gang 
territory map (Fig. 10) Sociologists created a gang territory map (Fig. 10) by utilizing a mixture of social media, history, gang iconography, and cultural phenomena to attempt to create boundaries that are in flux and that are invisible. As gang members attest, those boundaries exist. The next evolution in adding to the gang territory assessment consists of drill culture on social media. Being aware of drill culture can also serve as a measure of violence prevention and awareness.

Most gang maps are created by those immersed in gang culture, and the boundaries shift week-to-week, even if by small margins. Real-time gang mapping data, provided from civilian, police, and Tribune reports, could be broadcasted and shared, serving as a functional, open-source dataset for public use and device applications. The Tribune staff could use this dataset to report crime. They already employ algorithms that supply scores for mostly gang-affiliated persons (Gorner, 2016b). These scores reportedly aid in determining who is likely to shoot or get shot. Using these scores, police performed a raid and arrested 116 out of the top 140 people on the algorithm's output (Davey, 2016).

\section{Quality of life crime}

As shown in the findings, CPS reports and targets quality of life crime (drug use, possession, and sale; prostitution; disorderly conduct; and obstruction) as a tertiary response after violent crime and theft. By nature, drug crimes are difficult to report, as citizens often self-police, leading police officials to set up stings and drug busts, and offer preventive policing practices. But evidence has shown that drug crimes that are reported tend to offer hot spot areas, such as in the case of West Side communities (Humboldt 
Park, East Garfield, and West Garfield). Drugs are mostly associated with gangs, and, in turn, are associated with gun violence (Blumstein, 1995; Blumstein and Cork, 1996; Tita and Greenbaum, 2009).

As shown in Humboldt Park, which had the most quality of life crime, there were hot spots of drug offences. The Tribune was absent overall on reporting drug crime in Humboldt Park (as well as West Garfield and East Garfield). Collectively, however, the crimes amount to something much more dramatic and problematic. Many questions arise out of these types of crime, most importantly, "To what effect are these drug crimes harming the community?"

Tita and Greenbaum (2009) model drug markets with patterns of violence, arguing that Blumstein's hypothesis (Blumstein, 1995; Blumstein \& Cork, 1996) could be used to explain how drug markets "lead to the diffusion, and ultimate use, of guns among urban youth. Given that one cannot report the theft of one's drugs or drug money to the police, Blumstein argues that drug dealers armed themselves to protect against robbery" (p. 156). Furthermore, they add that the drug dealers" "arms race" leads directly to adjacent youth and young adults adopting the culture for both protection and bravado through residential contacts and public school interactions.

Tita and Greenbaum suggest using empiricism to address the problem between drug, gun, and gang interaction with territory and adjacent neighborhoods. "By combining gang turf maps with social network diagrams, it becomes possible to determine whether rival gangs are located in spatially adjacent areas, and thus the impact of gangs on spatial patterns of crime would be adequately captured in a simple contiguity matrix" (p. 156). The Law of Contiguity simply states, in this context, that crimes and 
crime patterns that occur in adjacent time/space can be readily associated with one another. If the Tribune is to cover shootings, they should cover illicit drug sales and use, as well as gang activity, when applicable to shootings and homicides. Of course, not all shootings and homicides are directly related to gang activity and/or drug sales and use, but in Chicago's case, a majority of these crimes are contiguous.

\section{Prostitution and Sex Crimes}

Prostitution was not covered in the Tribune in August 2016, but had been covered almost once a month in the past two years prior to August 2016. However, while the Tribune almost always publishes prostitution and/or sex crime stories after arrests have been made - such as prostitution stings, sex trafficking stings, and people caught trafficking teens and children for the sex trade - there exists an area of preventive reporting. By preventive reporting, a journalist may use crime data and community data to identify areas of prostitution and the sex trade in order to bring attention to both the area and to the community-at-large The media can serve a positive role in the effort to prevent crime and conflict rather than play the role as post-conflict reporter-sometimes making conflict worse by the act of sensationalizing "good" vs. "bad" components of society (Munteanu, 2011). By using Glitch Theory in this study, Crime Reports revealed a hot spot of prostitution and sex assault activity in West Englewood, along the corridor of South Ashland Drive. Police apparently did not perform a prostitution sting, because most arrests were made on different dates, and the Tribune did not report on any sting or arrests. While police may have concentrated their efforts in a particular neighborhood, demographic, or area, data suggests that this area simply has a lot of sex trade activity. 
The Tribune could act as a prevention vehicle by investigating the roots of prostitution and sex assault crime in West Englewood to discover other contiguous, aggravating factors.

\section{Sex Offenders}

Illinois state law carries many restrictions for registered child sex offenders. From a Glitch Theory perspective, the largest easily mapped restriction is proximity to schools. It is unlawful for a child sex offender or sexual predator to be present in any school building or property, or loiter within 500 feet of school property without the permission of the superintendent or school board, or in the case of a private school the principal, unless the child sex offender is a parent of a child at that school, and the parent is on school grounds to attend a parent-teacher conference (Illinois State Police 2016). Child sex offenders and sexual predators not only have to avoid social media, but they cannot be in contact with children in a social setting. This also includes parks, community centers, and isolated contact with children — even if a child belongs to a close friend. Because of this, sex offenders rarely live close to schools. Illinois law prohibits their living within 500 feet of a school or park.

Crime Reports allows users to access the sex offender database after the user acknowledges that the data will not be used in retribution against sex offenders and has read a disclaimer stating such. Sex offenders are listed by address, whereas some states only allow access to a localized address (such as by block or neighborhood). By filtering results, we can see how schools and parks act as buffers, creating oases of area free from sexual predators and child sex offenders. In one such example, a ring of schools and 
places of education form a ring, enclosing a high number of sex offenders within a neighborhood. Orr Academy High School is located in the lower left-hand portion of the map, and Cameron Elementary is in the upper right-hand. There are four other schools that form the enclosure (figs. 17-18). The schools' and parks' effect on where sex offenders live have two outcomes: schools and parks provide, in theory, safe spaces for children and their families to learn and play; and a larger amount of schools and parks can effectively force sex offenders into neighborhoods that aren't adjacent to a school or park. In this case, Humboldt Park has a populated neighborhood of about 11 blocks with 18 sex offenders - some of them violent. The Tribune almost exclusively reports on sex offenders and child sex offenders after they've committed a crime. There is little to no exploration on sex offender communities. A piece or series of pieces on living as a sex offender, or among sex offenders, can serve as a preventive measure for the public to learn about the differences of types of sex offenders, their rights and responsibilities, and the public's rights and responsibilities. Awareness and education serve as good deterrents in place of prison time or criminal repercussions.

\section{Alcohol and alcohol-selling establishments}

While difficult to establish overlapping gaps in data on alcohol-related crime when examining the Tribune and Crime Reports, there is an underlying responsibility to report alcohol-related crime. Many journalists and researchers are attempting to find ways to explore the rebirth of community journalism to explore responsible and ethical ways of responding to community issues such as alcohol abuse and related crime (Culver, 2016; Lehrman, 2016; Selvin, 2015). 
Crime Reports data underscore the difficulty in reporting on alcohol and alcoholrelated crime, as reports are rare and usually detail minors in possession, selling to minors, or businesses selling alcohol without a permit or license. If there is little crime data, how can the media report on issues? We know they are there, fueling domestic crime; aggravating violence; disrupting households; lowering inhibitions; and increasing chances that a person will do something against the law (Brantingham, et al., 2009; Paynich \& Hill 2010). Crime mapping by researchers have shown drinking establishments to be centers of clusters of crime (Brantingham, et al., 2009). Crime Reports clearly shows that clusters of drinking establishments create larger clusters of crime, as noted in the area by Wrigley Field. In fact, the clustering of crime outpaces many areas that are highly reported for other types of crime, such as those in West Side and South Side communities. Although the nature of crime may be less severe, there is obviously a toll on life, property, and well being of citizens in all areas-especially around drinking establishments.

Upon examination of Tribune reports, alcohol-related crime is mentioned only when the crime has a quality of sensationalism about it: A suburbanite woman was arrested for DUI, driving $4 \frac{1}{2}$ times over the legal limit; different parks "okay" the sale of alcohol within the park boundaries; a college student died of alcohol poisoning; a woman fighting her sister bit a police officer who intervened, etc. One article in the Health section described a man's journey of a "year without beer."

If the Tribune reporters could combine crime clusters and community journalism, they could find several stories worthy of reporting that, collectively, pose a significant health crisis issue to their readers. The instance of Wrigley Field crime appears to be a 
serious issue, especially during baseball season. In 2016, the Chicago Cubs won the World Series of Baseball, further boosting ticket sales and fan numbers that will flock to the drinking establishments in Wrigleyville in 2017.

\section{Watercraft and museums}

Burnham Harbor appeared to be a significant hotspot of theft, and breaking and entering, according to Crime Reports. The Tribune had no reports of crime in Burnham Harbor, yet the amount of crime was so significant, I made several calls to Chicago Police to discover more information. Two different officers reported that Crime Reports appeared to be using Burnham Harbor and the museums, as well as their parking lots, as one center point of crime reporting. This did not include Northerly Island (a peninsula enclosing the harbor) or the park district from Buckingham field up to Navy Pier. The reason why Crime Reports used Burnham Harbor as a plot point for Shedd Aquarium, Field Museum, Soldier Field, and Museum Campus is unknown and unclear.

There remain two problems: the addition of museums and their parking spaces increase the area and diffusion of crime, and there are thefts from watercraft at the end of summer - before the boats are wintered in anticipation of the freezing of Lake Michigan. The Tribune could serve their readers by offering a deeper investigation of crime in these areas-who are the criminals, who is being targeted, and how to prevent such issues as theft, vehicle theft, pickpocketing, and robbery? How can the city better protect citizens, their cars and their watercraft? 


\section{CONCLUSION}

Digital rhetoric exists not because of digital maps. It exists due to a developing path of discovery, innovation and persuasion. In Collin Gifford Brooke's Lingua Fracta (2009), he writes, "without sequence, order, development, or causality, the database as a cultural form would not seem to lend itself to the kind of discourse that we typically treat to rhetorical analysis" (p. 98), which is why Manovich's (2002) "new media objects don't tell stories," and why “they don't have a beginning or end." New media objects, such as overlapping maps, crime data plots and ethnographic data lines, fill in Brooke's sequence, order, development and causality. Order is made out of the Chicago Tribune's crime reporting sequences (2016); the New Aesthetic and Glitch Theory provide the development as the maps and data are combined, and the results demonstrate causality in manners that demonstrate both the obvious and non-obvious.

The New Aesthetic - a chronicling of the convergent, and often blurred, lines between the physical and digital - intersects with Glitch Theory on foundational and theoretical frameworks. While both the New Aesthetic and Glitch Theory are recent, $21^{\text {st }}$ century approaches to digital rhetoric and new media, their foundations can be applied, and seen, retroactively. Journalism, or the processes thereof, has used overlapping technologies to conduct and report research throughout recorded history. The symbiotic relationship between glitches and the chronicling of errata has shaped disciplines such as public health, environmental science, engineering, and sociology, for example. The Broad Street cholera outbreak in London, 1854, saw physician John Snow use patient and public data to create a map - thereby deducing, correctly, that a water pump caused an 
outbreak that killed over 600 citizens. His discovery also facilitated progress in science because scientists now knew that cholera was conveyed by water and wasn't “miasmatic." His discovery was a pre-digital example of today's use of provoking glitches in the system of databases of information. He created an overlapping boundary of public facilities, maps, and the locations of where the diseased and dying lived and worked.

Similarly, present-day, digital research can facilitate and provoke glitches in the system by juxtaposing overlapping technologies. By doing this with Crime Reports and the Tribune, we can see that both professional and amateur journalists can make discoveries about crime in their communities through the collision of database information. This research demonstrates that data glitches were discovered under the topics of sex offenders and urban space; arson clusters; the positive impact of schools on preventing crime; the lack of reporting on alcohol-related crime and baseball; gangs as self-policing forces; gangs as territorial criminals; and the presence of prostitution corridors. All of these discoveries could not have happened without overlapping boundaries of data. Additionally, these overlapping boundaries are but one of endless examples. Our digital culture is very good at generating data, but seemingly poor at knowing what to do with all of it.

Hopefully, the community will benefit the most from any findings referenced above. If the Tribune is able to capitalize on this new scope of inexpensive technology, such as Google Maps, perhaps we can bolster the community, digital newspaper as a source of integrity and ingenuity. Increasing news media credibility, lowering crime, 
raising crime awareness and learning research tools to understand crime in Chicago are but a few of the outcomes that this study wishes to reveal as a secondary goal.

On a more theoretical level, Glitch Theory and the New Aesthetic will discover new deficiencies or innovations in crime reporting, algorithmic racism and algorithmic sexism, and provide a foundational report on how to either capitalize on the innovations, employ the community to engage with the news media, or suggest changes to the Chicago Tribune's New Media reporting and engagement with the community.

The scope of this study is large, and there will be significant gaps left for discovery by further research and discourse. Many opportunities exist on examining the topics of self-policing and culture, race and demographics, the migration of guns and firearms from straw purchasers in Indiana to urban areas in Chicago, and a deeper exploration on drill rap and gang crime. This is an attempt to engender more community journalism in order to closely examine the roots of crime, and to tackle crime prevention instead of relying of post-fact crime reporting. The Tribune must ask itself if it wants to regard news as a post-fact industry, or a community-building industry. It could, in theory, be both. 


\section{WORKS CITED}

Ahmed-Ullah, N., Chase, J., \& Specter, B. (2013). “CPS approves largest school closure in Chicago history." Chicago Tribune. May 23, 2013. Accessed Jan. 17, 2017: http://articles.chicagotribune.com/2013-05-23/news/chi-chicago-school-closings20130522_1_chicago-teachers-union-byrd-bennett-one-high-school-program

Anderson, D. (2012). “Sediment.” Last modified December 12, 2015. http://vimeo.com/55546722.

Anderson, D., and Sayers, J. (2015) “The Metaphor and Materiality of Layers." Rhetoric and the Digital Humanities. Eds. Jim Ridolfo and William Hart-Davidson. The University of Chicago Press: Chicago.

Antunes, G.E. and Hurley, P.A. (1977). "The representation of criminal events in Houston's two daily newspapers.” Journalism Quarterly 54, 756-760.

Beauschesne, O. (2011) “Map of scientific collaborations from 2005 to 2009.” Available at: http://collabo.olihb.com.

Birner, B. (2012). Introduction to Pragmatics. John Wiley \& Sons: West Sussex, England.

Bizzell, P. and Herzberg, B. (2000). The Rhetoric of Tradition: Readings from Classical Times to the Present, $2^{\text {nd }}$ edition). London: Bedford/St. Martin's. Print.

Blumstein, A. (1995). "Youth Violence, Guns, and the Illicit-drug Industry." Journal of Criminology Law and Criminology, 86, 10-36.

Blumstein, A. and Cork, D. (1996). "Linking gun availability to youth gun violence. Law and Contemporary Problems, 59(1), 5-24 (special issue Kids, Guns, and Public Policy). 
Bosman, J., and Einhorn, C., (2016). "How One Brutal Weekend in Chicago Lives on for Time Team.” New York Times, Nov. 30, 2016. Accessed Nov. 31, 2016. https://www.nytimes.com/2016/11/30/insider/how-one-brutal-weekend-in-chicagolives-on-for-times-team.html.

Brantingham, P. L., Brantingham P. J., Vajihollahi, M., and Wuschke, K. (2009). "Crime Analysis at Multiple Scales of Aggregation: A Topological Approach.” Putting Crime in its Place: Units of Analysis in Geographic Criminology, 4, 87-107.

Bridle, J. (2011). About. New-Aesthetic.Tumblr.com/about. Accessed March 18, 2014 and June 28, 2015. http://new-aesthetic.tumblr.com/archive

Bridle, J. (2014). “How Street Maps Can Be Sexist.” FastCoExist. Accessed July 18, 2014 and July 2, 2015. http://new-aesthetic.tumblr.com/post/92136248690/how$\underline{\text { street-maps-can-be-sexist-coexist-ideas }}$

Brooke, C. G. (2009). Lingua Fracta: Towards a Rhetoric of New Media. Cresskill, New Jersey: Hampton Press. Print.

Butler, P. (2010) “Community mapping for intercultural dialogue.” EspacesTemps.net. Available at: http://www.espacestemps.net/document9252.html.

Caquard, S. (2014) “Cartography II: Collective cartographies in the social media era.” Progress in Human Geography, 38(1), 141-150.

City of Chicago. (2016). "City of Chicago Community Areas.” Web. Accessed December $2,2016$. https://www.cityofchicago.org/content/dam/city/depts/doit/general/GIS/Chicago_Map s/Community_Areas/Community Areas W Numbers.pdf. 
Culver, K. B. (2016) “Investing in Community News.” Editor \& Publisher [serial online]. 149(8) 46-51.

Daniel, S. L. (2002). Integrating Rhetoric and Journalism to Realize Publics. Rhetoric \& Public Affairs, 5(3), 507-524.

Davey, M. (2016). “Chicago Police Try to Predict Who May Shoot or Be Shot.” New York Times, May 23, 2016. Accessed Jan. 12, 2016. https://www.nytimes.com/2016/05/24/us/armed-with-data-chicago-police-try-topredict-who-may-shoot-or-beshot.html?action $=$ click\&contentCollection $=$ Times $\% 20$ Insider $\&$ module $=$ RelatedCove rage\&region=EndOfArticle\&pgtype $=$ article.

Donohue, G.A., Tichenor, P.J., and Olien, C.N. (1973). "Mass media functions, knowledge and social control. Journalism Quarterly 50, 652-659.

Elwood, S. and Leszczynski, A. (2011) "Privacy, reconsidered: New representations, data practices, and the geoweb." Geoforum 42(1): 6-15.

Geere, D. (2012). "Pareidolic robot looks for faces in clouds." Wired UK. Web. Accessed October 12, 2014.

“Glitch.” (2007) Oxford language dictionaries online [Oxford, England]: Oxford University Press, accessed July 20, 2015. Web.

GlobalFishingWatch.org. (2014) “A Technology Initiative to Illuminate Global Fishing Actively.” http://globalfishingwatch.org. Accessed May 23, 2015. Web.

Gorner, J. (2016a). "Few answers as Chicago hit with worst violence in nearly 20 years." Chicago Tribune, Dec. 30, 2016. 
http://www.chicagotribune.com/news/local/breaking/ct-chicago-violence-2016-met20161229-story.html.

Gorner, J. (2016b). "With violence up, Chicago police focus on a list of those likely to kill, be killed." Chicago Tribune, July 22, 2016.

http://www.chicagotribune.com/news/ct-chicago-police-violence-strategy-met20160722-story.html.

Graham, M. and Zook, M. (2011) "Visualizing global cyberscapes: Mapping usergenerated placemarks." Journal of Urban Technology 18(1): 115-132.

Hammer, S. (2015). "WR1T1NG (D1RTŸ) NEW MED1A / GL1TCH C0MP0S1TI0N.” technoculture: an online journal of technology in society: \#TCVol4Hammer. https://tcjournal.org/drupal/vol4/hammer. Accessed May 5, 2016. Web.

Hendersen, K., \& Lowell, Lt. R. (2000). "Reducing campus crime through high definition mapping." N. Lavigne \& J. Wartell (Eds.), Crime mapping case studies: Successes in the field, Vol. 2, 3-12). Washington, DC: Police Executive Research Forum.

Hocks, M. E. (June 01, 2003). Understanding Visual Rhetoric in Digital Writing Environments. College Composition and Communication, 54, 4, 629-56.

Kelley, M.J. (2013). "The emergent urban imaginaries of geosocial media." GeoJournal 78(1): 181-203.

Lehrman, S. (2016). “Tracie Powell: Improve police beat coverage.” Quill, 104(1), 38.

Lilly, P. (2012). "Nike+ FuelBand: One Big Security Hole For Your Life." Hot Hardware: The Hottest Tech Tested \& Burned In. http://hothardware.com/news/nikefuelband-one-big-security-hole-for-your-life. Accessed May 2, 2016. Web. 
Jackson, Linda A., et al. "Race, Gender, and Information Technology Use: The New Digital Divide." Cyberpsychology \& Behavior 11:4, 2008. Web.

Jerpi, L. (2011) “As Weather Warms Up, So Do Opportunities for Crime.” Legal \& Criminal Justice, Vol. 3.

Joiner, R., et al. (2012). “Gender, Internet Experiences, Internet Identification, and Internet Anxiety: A Ten-Year Followup.” Cyberpsychology, Behavior and Social Networking 15:7, 2012.

Lippmann, W. (1922). Public Opinion. Project Gutenburg, http://www.gutenberg.org/ebooks/6456.

Lipshultz, J.H., and Hilt, M.L. (2002). Crime and local television news: Dramatic, breaking, and live from the scene. Mahwah, NJ: Lawrence Erlbaum Associates.

Maguire, B., Sandage, D., and Weatherby, G.A. (1999). “Crime stories as television news: A content analysis of national, big city, and small town newscasts. Journal of Criminal Justice and Popular Culture 7, 1-14.

McConchie, A. (2015). “Hacker Cartography: Crowdsourced Cartography, OpenStreetMap, and the Hacker Political Imaginary.” ACME: An International EJournal for Critical Geographies 14:3, 2015, 874-898.

Paynich, R. and Hill, B. (2010). Fundamentals of Crime Mapping. Sudbury, Massachusetts: Jones and Bartlett Publishers. Print.

Peek, K. (2014). “Dawn of the Data Age.” Popular Science, 285(5), 53-59.

Perkins, C. (2013). "Plotting practices and politics: (im)mutable narratives in OpenStreetMap.” Transactions of the Institute of British Geographers Vol 39, 2013, 304-317. 
Perez, Jr., J. (2015). “CPS plans to consolidate several schools, close 2.” The Chicago

Tribune: December 1, 2015. Accessed May 2, 2016.

http://www.chicagotribune.com/news/ct-cps-school-consolidations-met-120220151201-story.html. Web.

Plummer-Fernandez, M. (2015). "In this essay I argue than an important recent development in the struggle to represent algorithms is that computer algorithms now have their own public domain.” \#algopop. Accessed January 18, 2015. http://algopop.tumblr.com/post/108459176118/in-this-essay-i-argue-that-animportant-recent

Reno, S. (1998). "Using crime mapping to address residential burglary.” N. Lavigne \& J. Wartell (Eds.), Crime mapping case studies: Successes in the field, Vol. 1, 15-33). Washington, DC: Police Executive Research Forum.

Ridolfo, J. and Hart-Davidson, W. (2015). Rhetoric and the Digital Humanities. Chicago: University of Chicago Press. Print.

Roncek, D. W. (2000). "Schools and crime.” V. Goldsmith, P.G. McGuire, J.H. Mollenkopf, \& T.A. Ross (Eds.), Analyzing crime patters: Frontiers of practice, 153168. Thousand Oaks, CA: Sage.

Roshier, B. (1973). “The selection of crime news by the press. In S. Cohen and J. Young (Eds.), The manufacture of news: A reader (pp. 28-39). Beverly Hills, CA: Sage. Routledge Companion to Remix Studies, The. (2015). Eds. Navas, E.; Gallagher, O.; burrough, x. New York, New York: Routledge. Print.

Sandvig, C. (2015). "Seeing the Sort: The Aesthetic and Industrial Defense of 'The Algorithm.' Journal of the New Media Caucus. Accessed August 2, 2015. 
http://median.newmediacaucus.org/art-infrastructures-information/seeing-the-sortthe-aesthetic-and-industrial-defense-of-the-algorithm/

Schwartz, A. (2014). "How Street Maps Can Be Sexist." Co.Exist.

Selvin, B. (2015). "Covering the Community." Nieman Reports, 69(1), 26-31.

Sheley, J.F., and Ashkins, C.D. (1981). "Crime, crime news, and crime views." Public Opinion Quarterly 45: 492-506.

Spencer, J. (2013). "List of Chicago Neighborhoods." TripAdvisor.com. Accessed December 2, 2016. Web. http://www.streetadvisor.com/chicago-cook-countyillinois/questions/list-of-chicago-neighborhoods.

Stewart, A. (2014). "Chicago rap in the looming aftermath of drill." Chicago Tribune. April 17, 2014. Accessed on Feb. 2, 2017. http://www.chicagotribune.com/entertainment/ct-chicago-rap-chief-keef-drill-sabaibn-inglor-20140417-story.html.

Stewart, F. (2016). "Dispatches from the Rap Wars: My 18 months inside one of Chicago's most notorious gangs." Chicago Magazine. Sept. 19, 2016. Accessed Nov. 12, 2016. http://www.chicagomag.com/Chicago-Magazine/October-2016/ChicagoGangs/.

Tita, G.E., and Greenbaum, R.T. (2009). "Crime, Neighborhoods, and Units of Analysis: Putting Space in its Place." Putting Crime in its Place: Units of Analysis in Geographic Criminology, eds. David Weisburd, Wim Bernasco, and Gerben J.N. Bruinsma. New York: Springer, LLC.

Venkatesh, S. (1999). "Midst the Handguns' Red Glare: Philanthropic Gangs and PoliceTenant-Gang Justice.” Whole Earth: Summer 1999. Wilson, M.W. (2011b) “Data 
matter(s): Legitimacy, coding, and qualifications-of-life." Environment and Planning D-Society and Space 29(5): 857-872.

Wikström, P. H. (2012). "Does Everything Matter? Addressing the Problem of Causation and Explanation in the Study of Crime." When Crime Appears: The Role of Emergence, McGloin, Sullivan, and Kennedy, eds. New York: Routledge.

Worsham, L. and Olson, Gary. (2008). Plugged In: Technology, Rhetoric, and Culture in a Posthuman Age. Cresskill, New Jersey: Hampton Press. Print.

Young, J. R. (2001). "Scholars Question the Image of the Internet as a Race-Free Utopia." Chronicle of Higher Education 48:5. Web.

Zhuang, Z. (2014). The Importance of Citizen Journalists in New Media when Reporting on Catastrophes. Global Studies Journal, 7(3), 21-39. 